\title{
THERMODYNAMIC PROPERTY EVALUATION AND MAGNETIC REFRIGERATION CYCLE ANALYSIS \\ FOR GADOLINIUM GALLIUM GARNET
}

R. W. Murphy

Energy Division

December 1994

\begin{abstract}
Prepared for
ADVANCED INDUSTRIAL CONCEPTS DIVISION

OFFICE OF INDUSTRIAL TECHNOLOGIES
\end{abstract}

Prepared by the

OAK RIDGE NATIONAL LABORATORY

Oak Ridge, Tennessee 37831 managed by

MARTIN MARIETTA ENERGY SYSTEMS, INC. for the

U.S. DEPARTMENT OF ENERGY under Contract No. DE-AC05-84OR21400

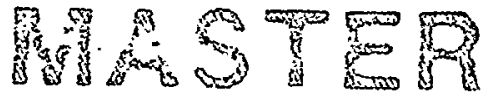




\section{DISCLAIMER}

This report was prepared as an account of work sponsored by an agency of the United States Government. Neither the United States Government nor any agency thereof, nor any of their employees, make any warranty, express.or implied, or assumes any legal liability or responsibility for the accuracy, completeness, or usefulness of any information, apparatus, product, or process disclosed, or represents that its use would not infringe privately owned rights. Reference herein to any specific commercial product, process, or service by trade name, trademark, manufacturer, or otherwise does not necessarily constitute or imply its endorsement, recommendation, or favoring by the United States Government or any agency thereof. The views and opinions of authors expressed herein do not necessarily state or reflect those of the United States Government or any agency thereof. 


\section{DISCLAIMER}

Portions of this document may be illegible in electronic image products. Images are produced from the best available original document. 


\section{CONTENTS}

FIGURES $\ldots \ldots \ldots \ldots \ldots \ldots \ldots \ldots \ldots \ldots \ldots \ldots \ldots \ldots \ldots \ldots \ldots \ldots$

ABSTRACT $\ldots \ldots \ldots \ldots \ldots \ldots \ldots \ldots \ldots \ldots \ldots \ldots \ldots \ldots \ldots \ldots \ldots \ldots \ldots \ldots \ldots \ldots$

1. INTRODUCTION $\ldots \ldots \ldots \ldots \ldots \ldots \ldots \ldots \ldots \ldots \ldots \ldots \ldots \ldots \ldots$

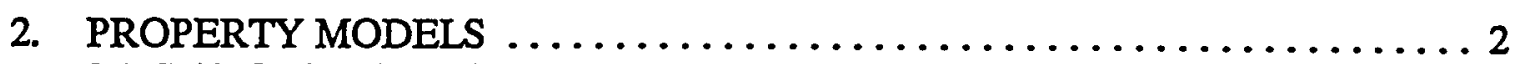

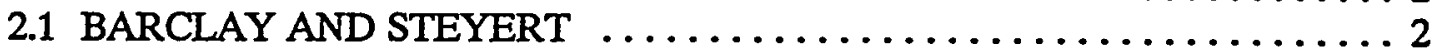

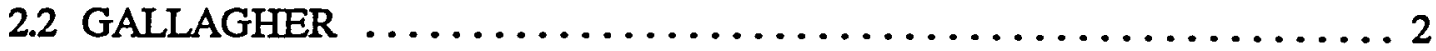

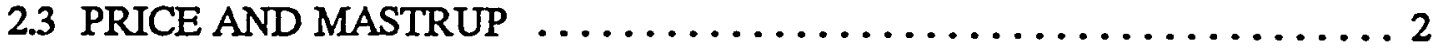

3. DATA/MODEL COMPARISONS-NO MAGNETIC FIELD $\ldots \ldots \ldots \ldots \ldots \ldots 4$

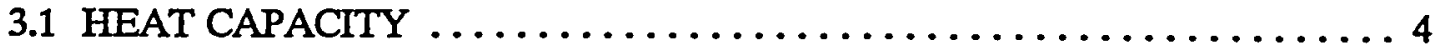

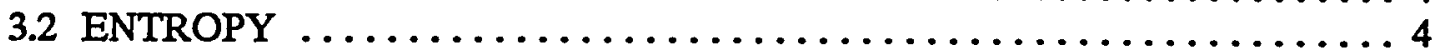

4. DATAMODEL COMPARISONS WITH MAGNETIC FIELD . . . . . . . 8

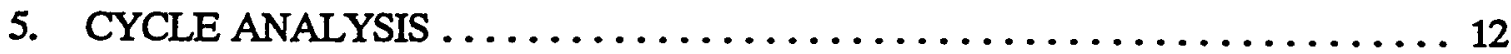

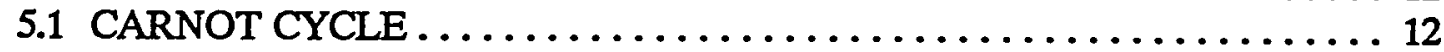

5.2 IDEAL REGENERATIVE CYCLE . . . . . . . . . . . . . . . 12

5.3 PSEUDO-CONSTANT FIELD REGENERATTVE CYCLE . . . . . . . . 17

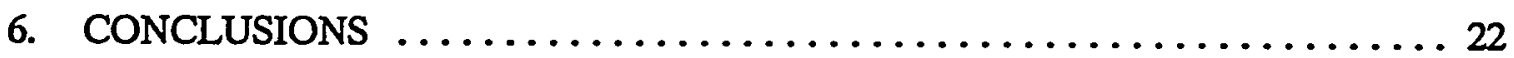

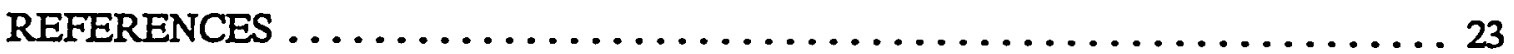

APPENDIX: FORTRAN COMPUTER CODE FOR MODELING MAGNETOTHERMODYNAMIC PROPERTIES

OF GADOLINIUM GALLIUM GARNET .............. 25 


\section{ACKNOWLEDGMENTS}

This work is part of the Thermal Sciences Research Program sponsored by the Advanced Industrial Concepts Division of the U.S. Department of Energy (DOE). The author appreciates the program support of M. E. Gunn and E. P. HuangFu of DOE; the technical suggestions of F. C. Chen, V. C. Mei, and G. L. Chen; and the publications assistance of D. M. Counce and M. D. Bunner. 



\section{FIGURES}

1. Heat capacity with zero magnetic field $\ldots \ldots \ldots \ldots \ldots \ldots \ldots \ldots \ldots, \frac{\text { Page }}{5}$

2. Entropy with zero magnetic field (low temperature) $\ldots \ldots \ldots \ldots \ldots \ldots, 6$

3. Entropy with zero magnetic field (high temperature) $\ldots \ldots \ldots \ldots \ldots \ldots, 7$

4. Comparison of magnetization models $\ldots \ldots \ldots \ldots \ldots \ldots \ldots \ldots \ldots, 9$

5. Heat capacity at low magnetic fields $\ldots \ldots \ldots \ldots \ldots \ldots \ldots \ldots \ldots \ldots, 10$

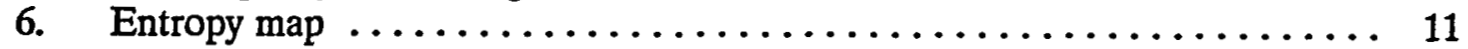

7. Limits on isentropic temperature rise and isothermal entropy drop ...... 13

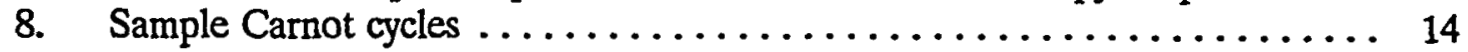

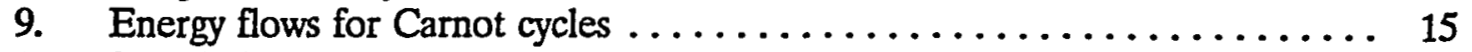

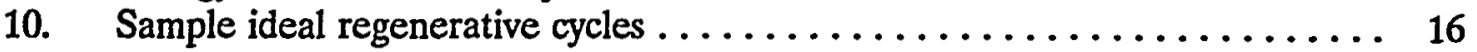

11. Energy flows for ideal regenerative cycles $\ldots \ldots \ldots \ldots \ldots \ldots \ldots \ldots \ldots, 18$

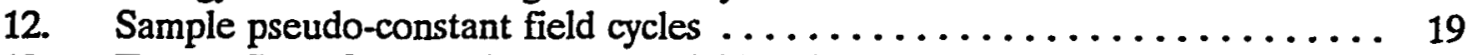

13. Energy flows for pseudo-constant field cycles $\ldots \ldots \ldots \ldots \ldots \ldots \ldots \ldots 20$

14. Relative performance of ideal regenerative and pseudo-constant field cycles . 21

15. Entropy/temperature/magnetic field surface $\ldots \ldots \ldots \ldots \ldots \ldots \ldots \ldots, 35$ 
- 


\begin{abstract}
Based on relevant material property data and previous model formulations, a magnetothermodynamic property map for gadolinium gallium garnet $\left(\mathrm{Gd}_{3} \mathrm{Ga}_{5} \mathrm{O}_{12}\right)$ was adapted for refrigeration cycle analysis in the temperature range $4-40 \mathrm{~K}$ and the magnetic field range 0-6 T. Employing methods similar to those previously developed for other materials and temperature ranges, assessments of limitations and relative performance were made for Carnot, ideal regenerative, and pseudo-constant field regenerative cycles. It was found that although Carnot cycle limitations on available temperature lift for gadolinium gallium garnet are not as severe as the limitations for materials previously examined, considerable improvement in cooling capacity and temperature lift combinations can be achieved by using regenerative cycles if serious loss mechanisms are avoided.
\end{abstract}




\section{INTRODUCTION}

The basic principles of magnetic refrigeration have been recognized for many years. Recently, interest in this area has increased because of such factors as the promise of the availability of high temperature superconductors for magnet applications, the search for refrigerant alternatives to reduce ozone depletion and global warming contributions, and the emphasis on increasing energy efficiency in industrial processes.

The attractiveness of $\mathrm{Gd}_{3} \mathrm{Ga}_{5} \mathrm{O}_{12}$, also called gadolinium gallium garnet or $\mathrm{GGG}$, as a low-temperature magnetic refrigerant has been summarized very well by Barclay and Steyert. ${ }^{1}$ Measurements of relevant GGG material properties have been made by Onn et al., ${ }^{2}$ Hornung et al., ${ }^{3-5}$ Barclay and Steyert, Daudin et al., ${ }^{6}$ Antyukhov et al., ${ }^{7}$ Hashimoto et al., ${ }^{8}$ and Dai et al. ${ }^{9}$ In single crystals, the effects of orientation and dislocations have been examined. For sintered material, density effects have been investigated. Notable efforts to model magnetothermodynamic properties of GGG include those of Barclay and Steyert, Daudin et al., Gallagher ${ }^{10}$ Dai et al., and Price and Mastrup. ${ }^{11}$ A number of working devices also have been constructed to provide useful refrigeration. Most of these have been of the Carnot type, but in some cases, regenerative concepts have been used.

In previous efforts, we have developed methods for modeling other magnetocaloric materials and for assessing the limitations and performance of specified regenerative and nonregenerative refrigeration cycles. ${ }^{12,13,14}$ In this report, we attempt to apply those methods to extend our assessments to the low-temperature range of interest for GGG, using existing models modified appropriately in recognition of relevant property data. 


\section{PROPERTY MODELS}

\section{BARCLAY AND STEYERT}

Barclay and Steyert used the summation of two terms, one representing the lattice component and one representing the magnetic component, to describe heat capacity and entropy variations with temperature and magnetic field. ${ }^{1}$ The lattice contribution to the heat capacity was regarded as being independent of field and proportional to the cube of temperature (in the traditional fashion of Debye-type materials at temperatures far below the Debye characteristic temperature) with the proportionality constant found by Onn et al. for temperatures up to $4.2 \mathrm{~K}$ (ref.2) and supported by Barclay and Steyert data up to $25 \mathrm{~K}$ (ref.1). Direct integration from zero to the temperature of interest was used to provide the lattice contribution to the total entropy. For zero field, the magnetic contribution to the entropy was represented by the difference in two terms based on work by Pratt et al.: ${ }^{15}$ the first was the constant full magnetic entropy for the total electron orbital momentum quantum number of the material; the second was proportional to the inverse square of the ratio of the temperature of interest to the effective Néel temperature ( $2 \mathrm{~K}$ here). Differentiation of the second term was used to provide the magnetic contribution to the total heat capacity at zero field. For non-zero fields, Barclay and Steyert employed a molecular field model with associated internal fields to characterize antiferromagnetic ordering aspects of the material and to generate the relevant partition function, magnetic entropy, and magnetic heat capacity.

\section{GALLAGHER}

To represent the zero-field heat capacity up to $25 \mathrm{~K}$, Gallagher used a three-term polynomial function of temperature combining an electronic contribution based on Fisher et $\mathrm{al}^{3}$ for temperatures up to $4.2 \mathrm{~K}$ with a lattice contribution based on Onn et al. ${ }^{2}$ up to $4.2 \mathrm{~K}$ and on Barclay and Steyert ${ }^{1}$ up to $25 \mathrm{~K}$ To model non-zero field effects, he used the magnetization data of Brodale et al..$^{5}$ (for temperatures from 0.5 to $4.2 \mathrm{~K}$ and fields from 0.1 to $9.0 \mathrm{~T}$ ) and Hashimoto ${ }^{8}$ (for temperatures from 4 to $25 \mathrm{~K}$ and fields from 0.3 to $9.0 \mathrm{~T}$ ) to deduce an empirical magnetization function of temperature and field. He then integrated that function numerically from zero field to the field of interest by means of Gauss-Legendre quadrature to provide heat capacity and entropy values.

\section{PRICE AND MASTRUP}

For both zero and non-zero fields, Price and Mastrup constructed the magnetothermodynamic Gibbs function as the sum of electronic and lattice components. ${ }^{11}$ The electronic contribution was deduced directly from the electronic partition function resulting from the crystal energy level structure suggested by Dai et al. ${ }^{9}$ For the lattice contribution, the small compressibility assumption for solids was invoked to justify approximating the Gibbs free lattice energy by the Helmholtz free lattice energy. Then the associated lattice heat capacity was represented with a variable Debye temperature form of the low temperature approximation to the Debye integral. In particular, a quadratic 
temperature dependence approximation to the Debye temperature was deduced from the zero-field heat capacity data of Hornung et al., ${ }^{4}$ Daudin et al., ${ }^{6}$ and Dai et al. based on the apparent Debye temperature at $0 \mathrm{~K}$, the minimum value for the Debye temperature, and the temperature at which the minimum occurs. Employing all these methods, we developed the explicit closed form representations for the resulting lattice integral expressions and combined them with the partition function-based electronic contribution to generate the magnetothermodynamic Gibbs function from which all remaining thermodynamic properties-including entropy, enthalpy, internal energy, Helmholtz free energy, magnetization, and total heat capacity at constant magnetic field-can be deduced. The resulting Fortran computer code is presented in the Appendix. 


\section{DATA/MODEL COMPARISONS-NO MAGNETIC FIEILD}

\subsection{HEAT CAPACITY}

Figure 1 shows very good agreement above $0.6 \mathrm{~K}$ between the Price and Mastrup model ${ }^{11}$ and data from two of its indicated sources for the Debye characteristic fits, Hornung et al. ${ }^{4}$ and Dai et al. ${ }^{9}$ Since Dai et al. indicate excellent agreement between their data and those of the remaining source, Daudin et al., ${ }^{6}$ for 4-30 K, Fig. 1 verifies very good agreement of the Price and Mastrup model with the zero-field heat capacity data on which it was based. In addition, the model shows comparable agreement with the single crystal cluster data of Onn et al. ${ }^{2}$ above $0.6 \mathrm{~K}$ in Fig. 1 . Excellent agreement was found between the model and the data of Antyukhov et al. ${ }^{7}$ over the range $4.5-30 \mathrm{~K}$. Additional comparisons showed that the sintered sample data of Onn et al. were lower than the values predicted by the model below $1 \mathrm{~K}$ and higher above $2 \mathrm{~K}$ (up to $4 \mathrm{~K}$ ), and that the single crystal data of Barclay and Steyert ${ }^{1}$ were consistently higher than the values from the model (4-25 K). In summary, the very good low-temperature agreement with Onn et al. single crystal, Hornung et al., and Dai et al. data-plus the very good hightemperature agreement with Daudin et al., Antyukhov et al., and Dai et al. data-seem to provide substantial validation of the model under zero-field conditions.

Both the Barclay and Steyert model and the Gallagher model ${ }^{10}$ appear to offer inferior agreement with most of the zero-field data. The Barclay and Steyert model, in particular, seems to give values that are higher than the data between 0.5 and $1.0 \mathrm{~K}$, lower than the data between 1 and $9 \mathrm{~K}$, and higher than the data between 9 and $40 \mathrm{~K}$. The Gallagher model seems to give values that are lower than the data between 0.5 and $1.0 \mathrm{~K}$, about equal to the data from 2 to $6 \mathrm{~K}$, and higher than the data between 6 and $40 \mathrm{~K}$. Consistent with the judgment of Dai et al. that earlier studies had underestimated the effective Debye temperatures of this material, it appears that both the Barclay and Steyert model and the Gallagher model overestimate the lattice contribution to the heat capacity, which dominates for temperatures above about $10 \mathrm{~K}$.

\subsection{ENTROPY}

By their fundamental nature, both the Price and Mastrup model and the Barclay and Steyert model give explicit values for entropy as a function of temperature with zero magnetic field. However, the polynomial nature of the Gallagher model requires the selection of a reference entropy at some finite temperature (Gallagher chose his reference entropy value to be zero at $1 \mathrm{~K}$, zero field) to generate such values for a range of temperatures. For convenience in comparisons here, because the Gallagher model was based in part on data sets from Hornung et al., we have chosen to set the Gallagher model entropy value at $2 \mathrm{~K}$, equal to the experimental entropy value reported by Hornung et al. at $2 \mathrm{~K}$. Then all other Gallagher model values are calculated relative to this established baseline.

Figure 2 shows excellent agreement for temperatures from 0.5 to $5 \mathrm{~K}$ between the Price and Mastrup model and data from Hornung et al. and Dai et al. As expected, because the polynomial approximation used in the Gallagher model is based on data from the series taken by Hornung et al., the associated data/model agreement shown in Fig. 2 


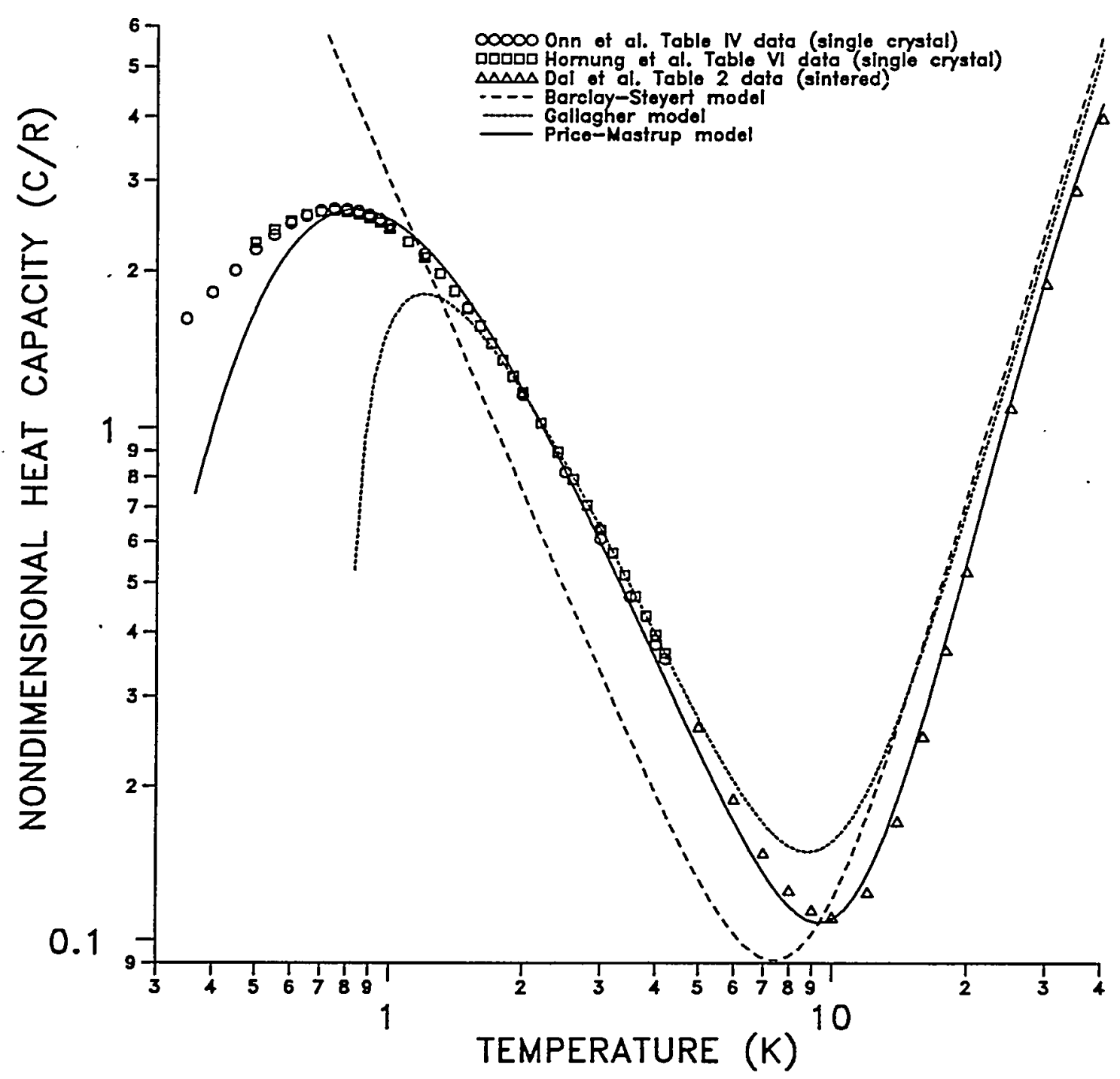

Fig. 1. Heat capacity with zero magnetic field.

from 1.5 to $5 \mathrm{~K}$ is outstanding. Below $1.5 \mathrm{~K}$, the fit of the electronic component (dominant in this temperature range) of the polynomial fit breaks down, and the Gallagher model values exceed the data down to $0.5 \mathrm{~K}$. The Barclay and Steyert model substantially overpredicts the data values in Fig. 2 down to about $0.75 \mathrm{~K}$.

When the temperature range is extended to $40 \mathrm{~K}$, as shown in Fig. 3, the superior agreement of the Price and Mastrup model with the Dai et al. data is clear. Although the Gallagher model appears to provide excellent agreement up to $10 \mathrm{~K}$, it overpredicts the data for higher temperatures. The overprediction tendency of the Barclay and Steyert model decreases up to $10 \mathrm{~K}$, but increases again up to $40 \mathrm{~K}$. As indicated earlier, both the Gallagher and the Barclay and Steyert overprediction tendencies at temperatures above $10 \mathrm{~K}$ can be attributed to their overestimating the size of the lattice component, which dominates in this higher temperature range. 


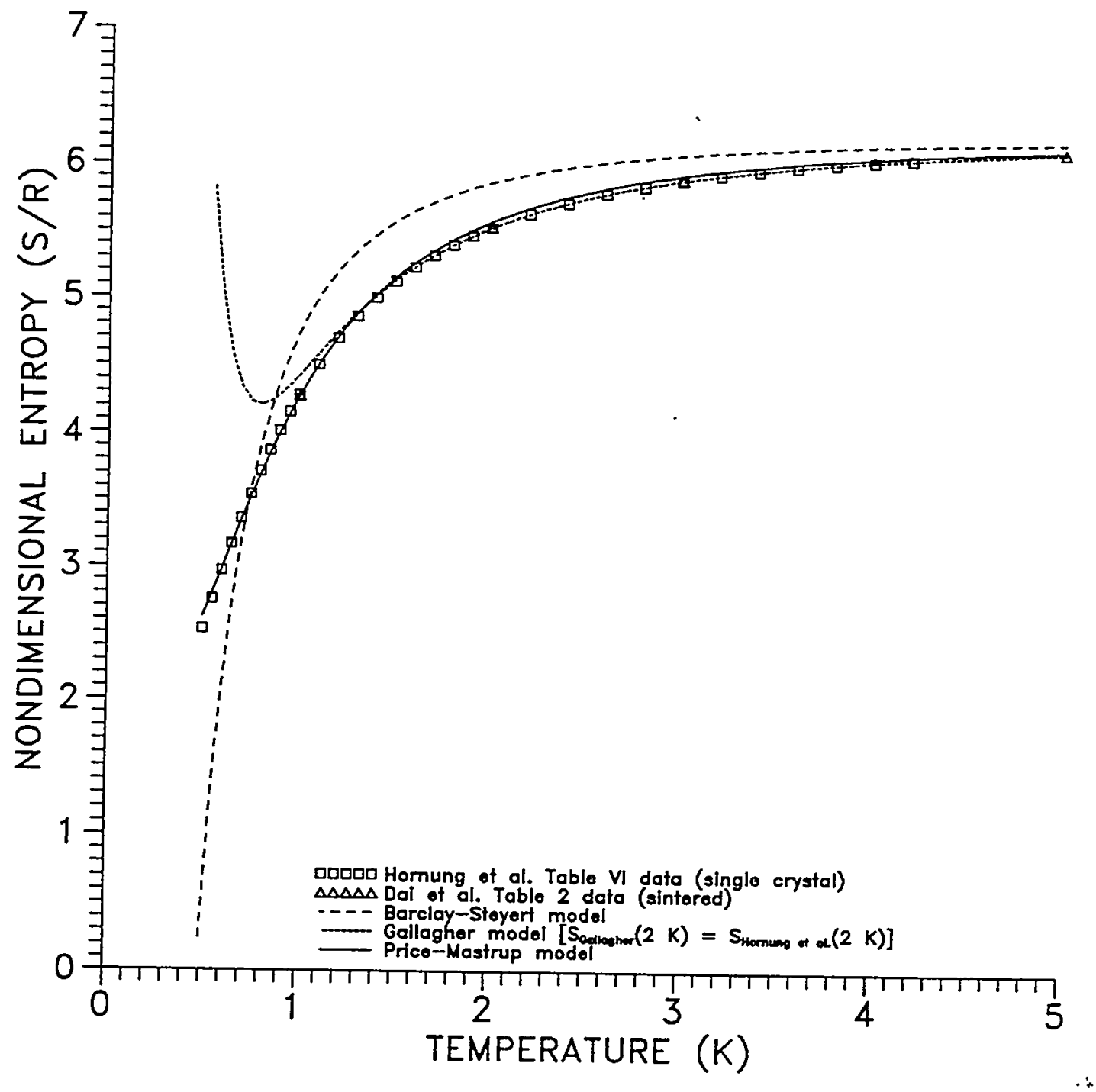

Fig. 2. Entropy with zero magnetic field (low temperature). 


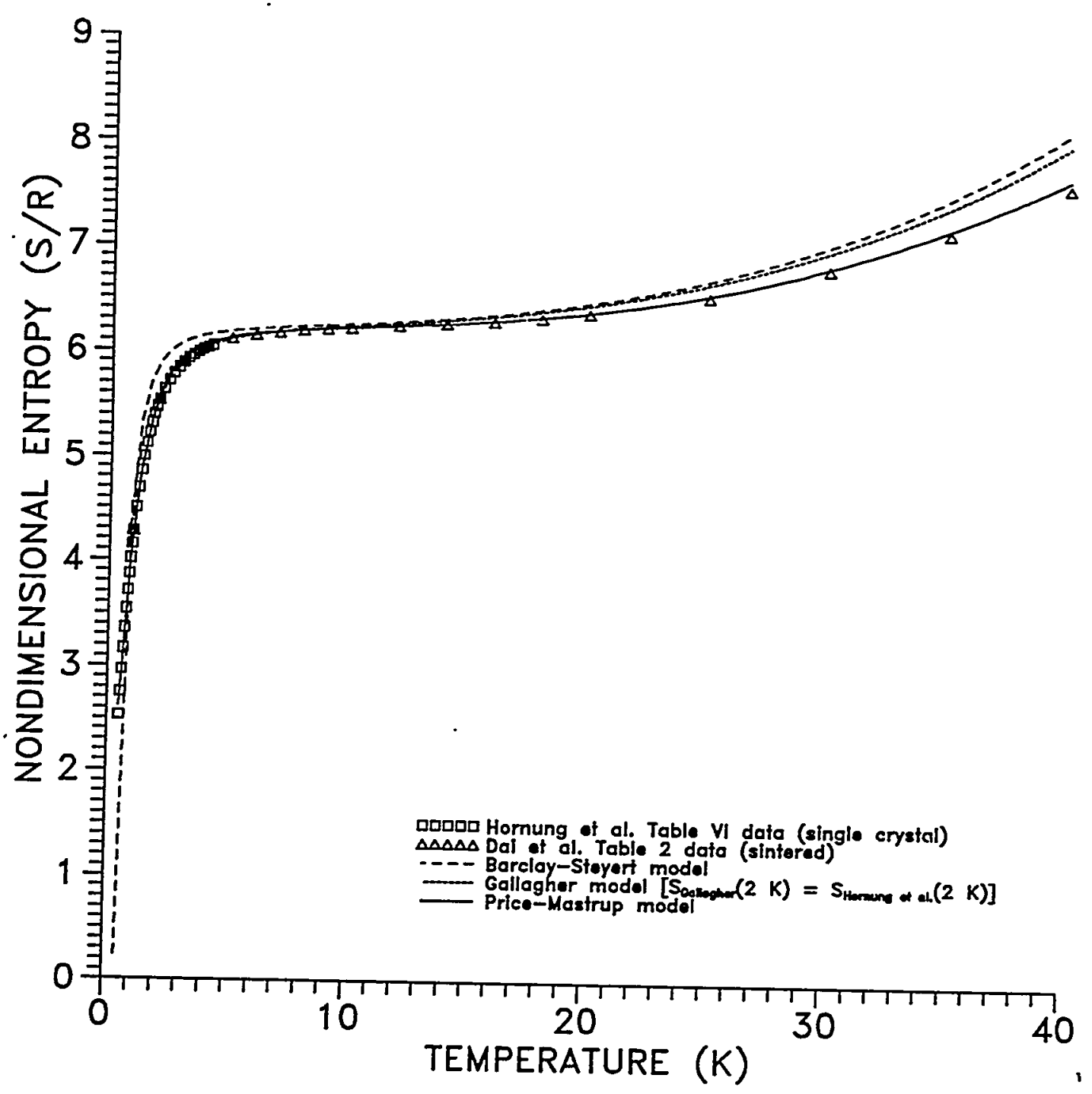

Fig. 3. Entropy with zero magnetic field (high temperature). 


\section{DATA/MODEL COMPARISONS WITH MAGNETIC FIELD}

In his work, Gallagher ${ }^{10}$ found that the molecular field model employed by Barclay and Steyert ${ }^{1}$ did not provide magnetization predictions that agreed well with the data of Hashimoto ${ }^{8}$ and Hornung et al. $^{4}$ at low temperatures and fields. He developed an empirical formulation of magnetization as a function of temperature and field to describe the data more accurately. He judged the resulting fits to be much more accurate than other existing magnetization formulations, with only slight mismatches for temperatures below $4 \mathrm{~K}$ at fields above $7 \mathrm{~T}$. Accounting for demagnetization effects, Dai et al. ${ }^{9}$ deduced energy level sequences based on three distinct eigen states which, for temperatures above $1.5 \mathrm{~K}$, provided accurate representation of both their data $(4-30 \mathrm{~K}, 0.1-4.0 \mathrm{~T})$ and those of Hornung et al. $(0.5-4.2 \mathrm{~K}, 0.1-9.0 \mathrm{~T})$. Figure 4 demonstrates that the Price and Mastrup model, which incorporates these energy level sequences to form the associated electronic partition function, gives magnetization values in very good agreement with those from the Gallagher model over wide ranges in temperature and field.

Based on the information presented, it appears that the Price and Mastrup model reliably characterizes both zero-field heat capacity as a function of temperature and magnetization as a function of temperature and field. The comparisons provide a measure of confidence that the model will produce reliable predictions of the remaining magnetothermodynamic properties (especially heat capacity and entropy for finite fields) within the defined temperature and field ranges.

Additional checks were made by comparing measured heat capacities at various fields with values calculated from the model. As illustrated in Fig. 5, Dai et al. noted that, for temperatures below $4 \mathrm{~K}$ and fields below $2.5 \mathrm{~T}$, calculated heat capacities vary somewhat from those measured by Hornung et al. They attributed those variations to degeneracies reflecting crossings in the suggested energy level map. As expected, because the crystal energy level structure suggested by Dai et al. was employed in the Price and Mastrup model, ${ }^{11}$ the heat capacity data from Dai et al. agreed well with the model over the temperature range of 4 to $30 \mathrm{~K}$ and the field range of 0.5 to $6.0 \mathrm{~T}$. The degree of agreement between the model predictions of heat capacities and the data of Barclay and Steyert and Daudin et $a .^{6}$ was approximate, but not as good as that for the other data mentioned earlier.

A final check was made between model predictions and data for adiabatic temperature drop reported by Hashimoto et al. For two fields, $3.26 \mathrm{~T}$ and $4.65 \mathrm{~T}$, and maximum temperatures of 10 to $30 \mathrm{~K}$, the Price and Mastrup model predictions were in good agreement with the data, but the Gallagher model substantially underpredicted the adiabatic temperature drops for maximum temperatures above $20 \mathrm{~K}$.

Based on the validation of the Price and Mastrup model over the ranges $4-40 \mathrm{~K}$ and 0-6 T, it was used to construct temperature-entropy plots for selected fields as shown in Fig. 6. 


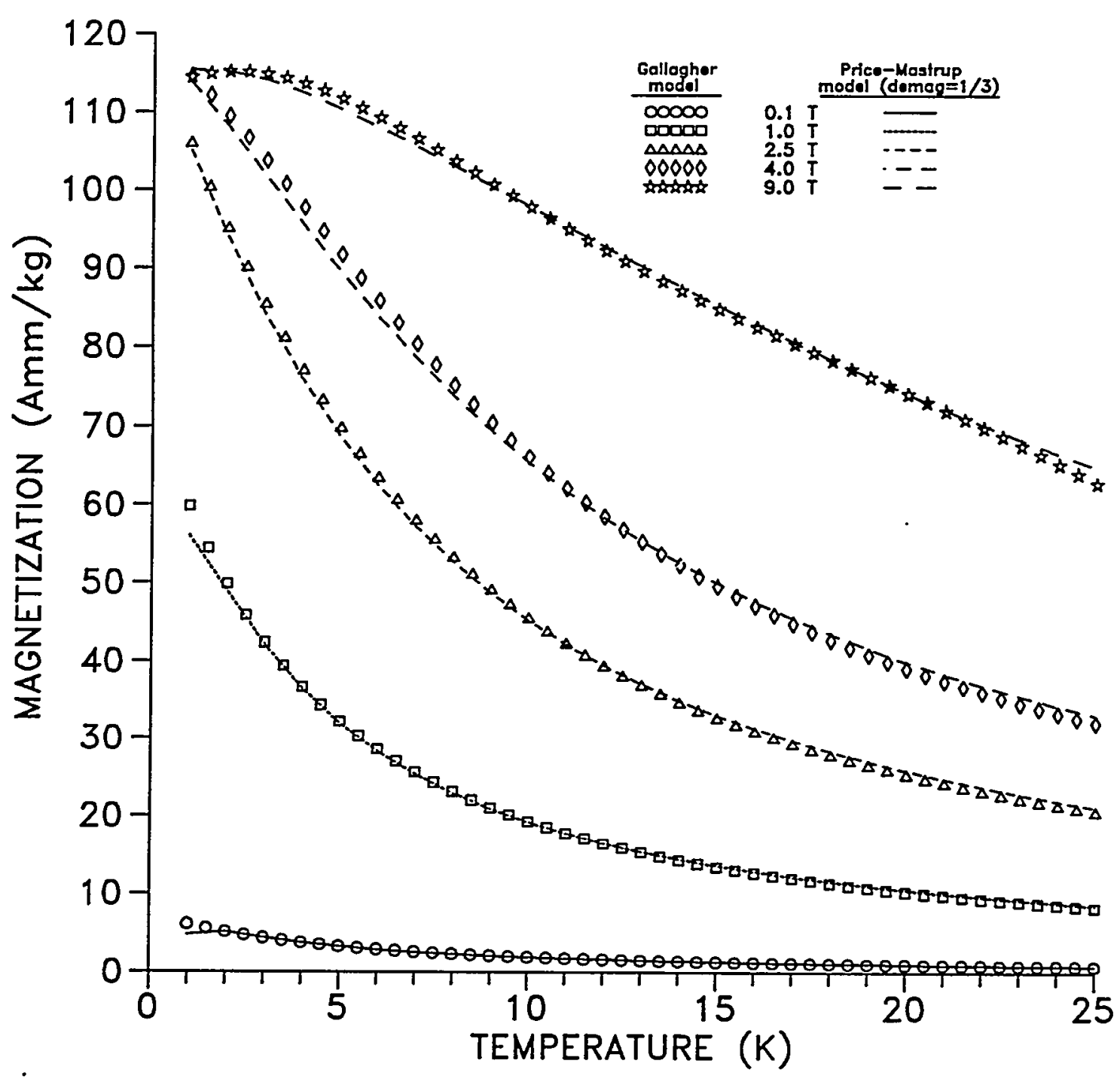

Fig. 4. Comparison of magnetization models. 


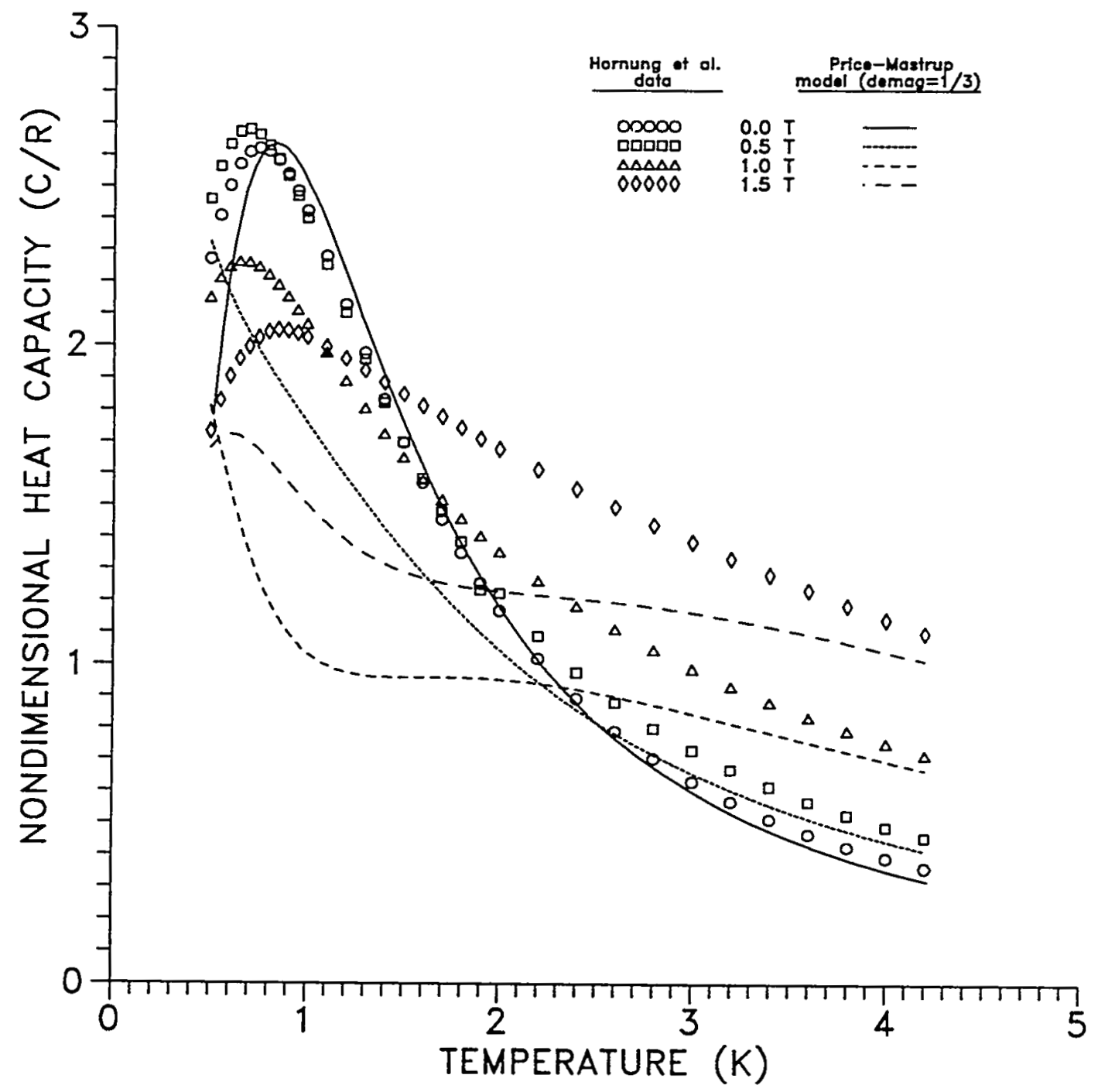

Fig. 5. Heat capacity at low magnetic fields. 


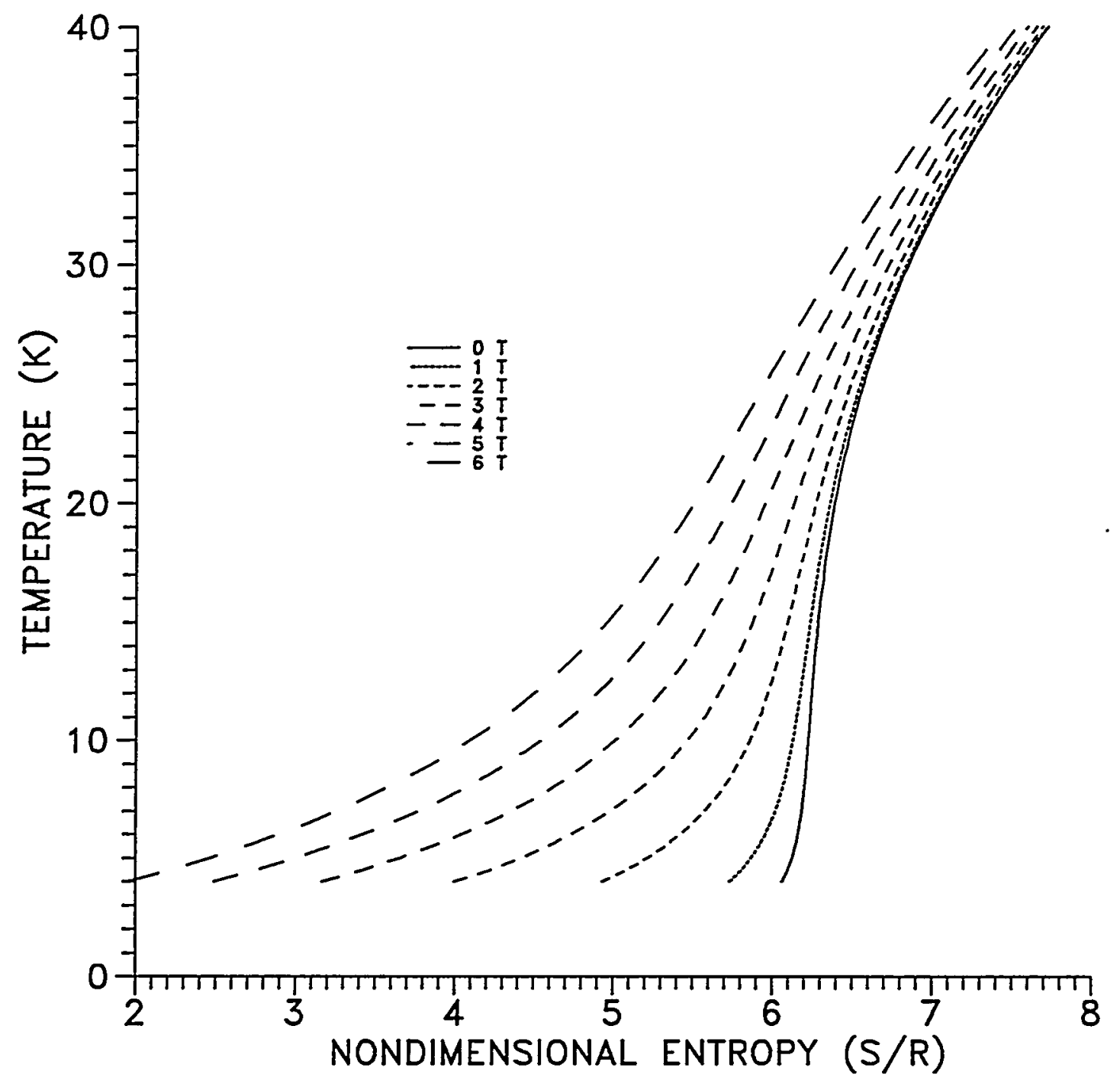

Fig. 6. Entropy map. 


\section{CYCLE ANALYSIS}

The material temperature-entropy map is the starting point for analyzing candidate refrigeration cycles. Methods that we developed previously ${ }^{12}$ were employed to examine the relative limits and performance of three types of refrigeration cycles for which both the net cooling and heat rejection processes are isothermal: the Carnot, the ideal regenerative, and the pseudo-constant field regenerative. As indicated in Fig. 7, for a given cooling temperature ( $4 \mathrm{~K}$ for the example presented here) and given maximum and minimum fields ( $6 \mathrm{~T}$ and $0 \mathrm{~T}$ here), limits are established by the material temperatureentropy-field map on the available isothermal entropy drop and on the available isentropic temperature rise. For a material with a map like the one shown here for GGG, the first limit establishes an upper bound on cooling capacity (135 J/kg here) for all candidate cycles. The second limit establishes an upper bound on refrigeration temperature lift (22 $\mathrm{K}$ here) for nonregenerative cycles like Carnot.

\subsection{CARNOT CYCLE}

Illustrated in Fig. 8, the Carnot cycle combines the two isothermal processes with two isentropic processes. As the heat rejection temperature rises above the cooling temperature, the available isothermal entropy change (the difference between the entropy of the low-temperature, low-field corner and the high-temperature, high-field corner of the cycle) decreases very rapidly, implying a correspondingly rapid decrease in cooling capacity (see the energy flow components of Fig. 9) until cooling capacity vanishes at a heat rejection temperature of $26 \mathrm{~K}$. However, in the case of the heat rejection component, the effect of the increasing heat rejection temperature overwhelms that of the decreasing isothermal entropy change up to the heat rejection maximum at $8 \mathrm{~K}$. From that point, the heat rejection falls rapidly and necessarily reaches zero to match the cooling capacity at $26 \mathrm{~K}$. The work input component rises to a peak at $13 \mathrm{~K}$ and subsequently falls rapidly to vanish with the other two components at $26 \mathrm{~K}$. By its very nature, this cycle maintains maximum cooling coefficient of performance (COP) over its entire operating range (a quite substantial range because of the outstanding properties of this refrigerant). However, if greater temperature lifts are required, alternative cycles must be considered.

\subsection{IDEAL REGENERATTVE CYCLE}

In theory, as explained previously, the ideal regenerative cycle can take full advantage of the field- and temperature-bounded operating region. To minimize thermal storage requirements (as illustrated by the family of cycles in Fig. 10), we have chosen to have the nonisothermal segments of the ideal regenerative cycle consist of a constant low field (actually zero field here) recovery path and a varying high field storage path that maintains a fixed horizontal separation on temperature-entropy coordinates. As the heat rejection temperature rises above the cooling temperature, the available isothermal entropy change again drops. However, the magnitude of this term-determined by the horizontal distance between the low and high field lines at the heat rejection temperature-decreases more slowly than in the Carnot example. Therefore, the ideal 


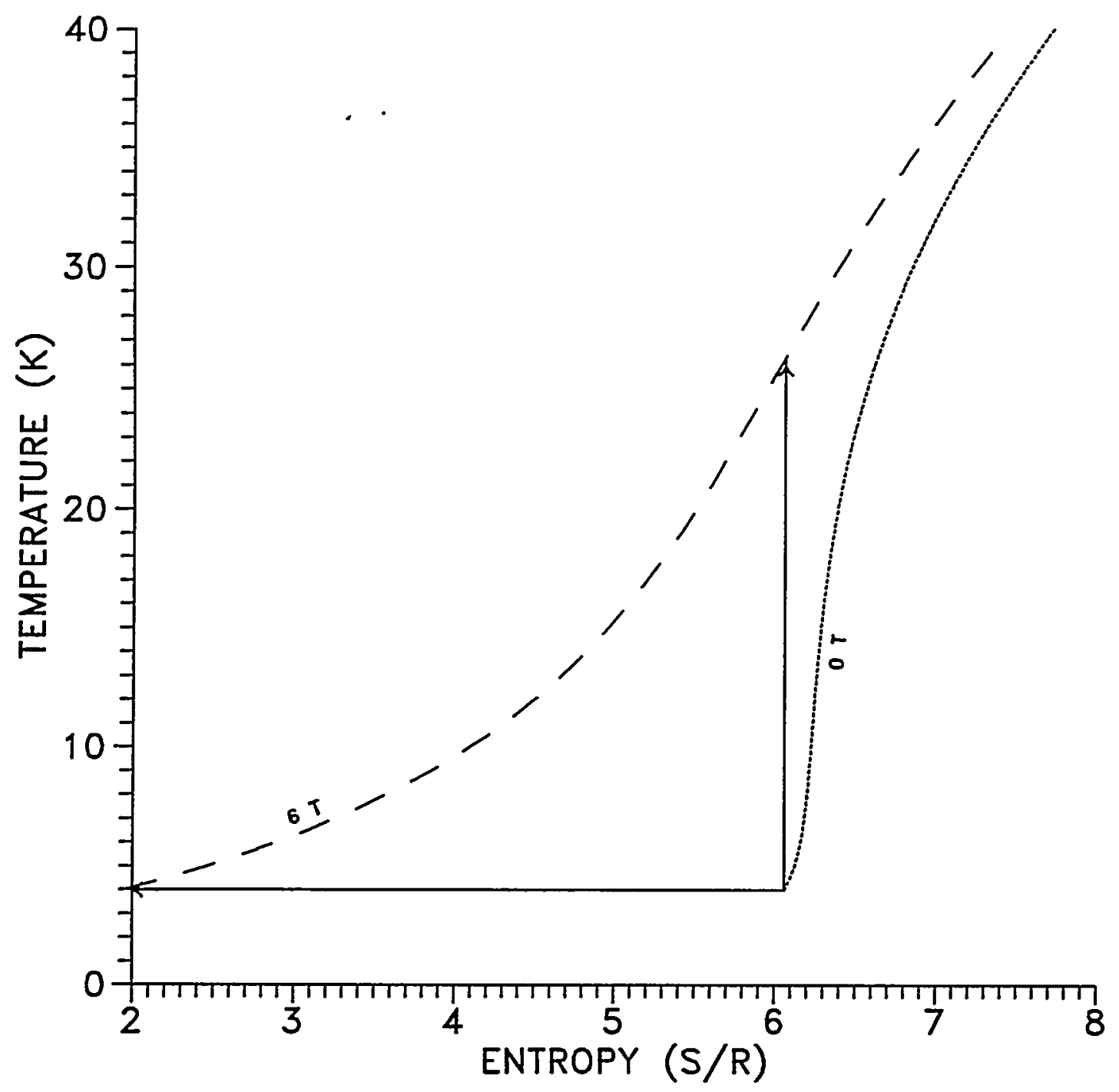

Fig. 7. Limits on isentropic temperature rise and isothermal entropy drop. 


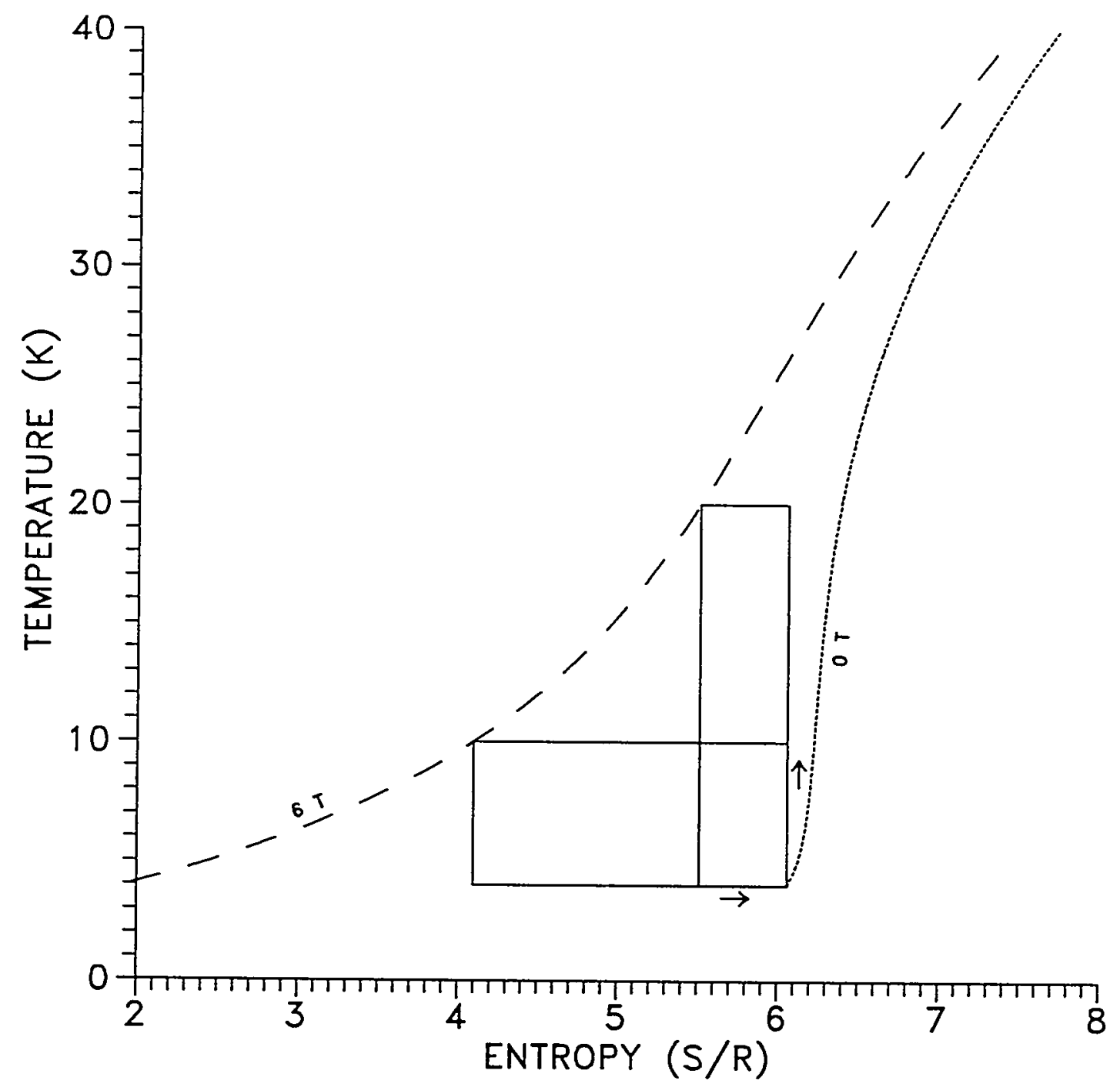

Fig. 8. Sample Carnot cycles. 


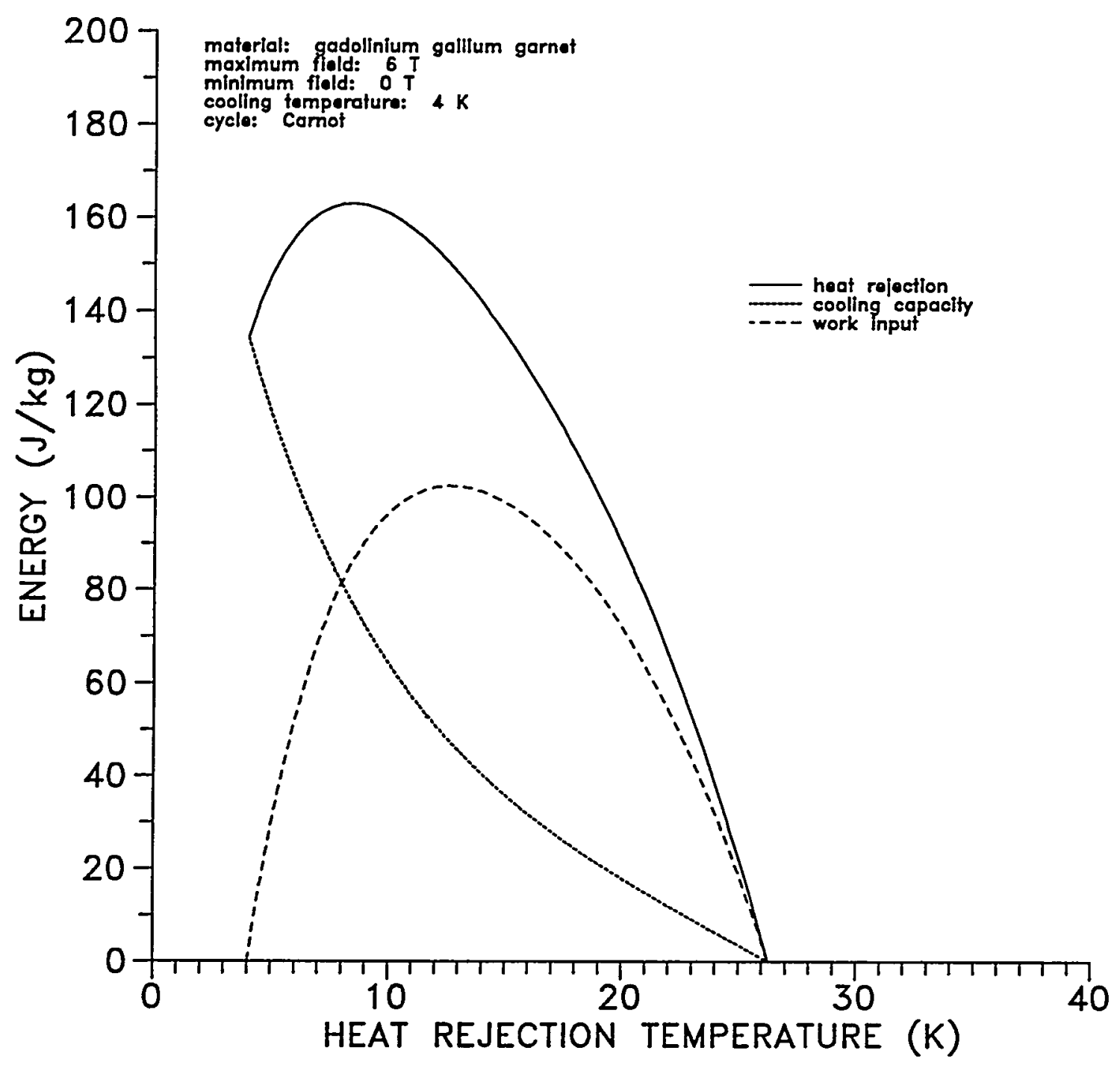

Fig. 9. Energy flows for Carnot cycles. 


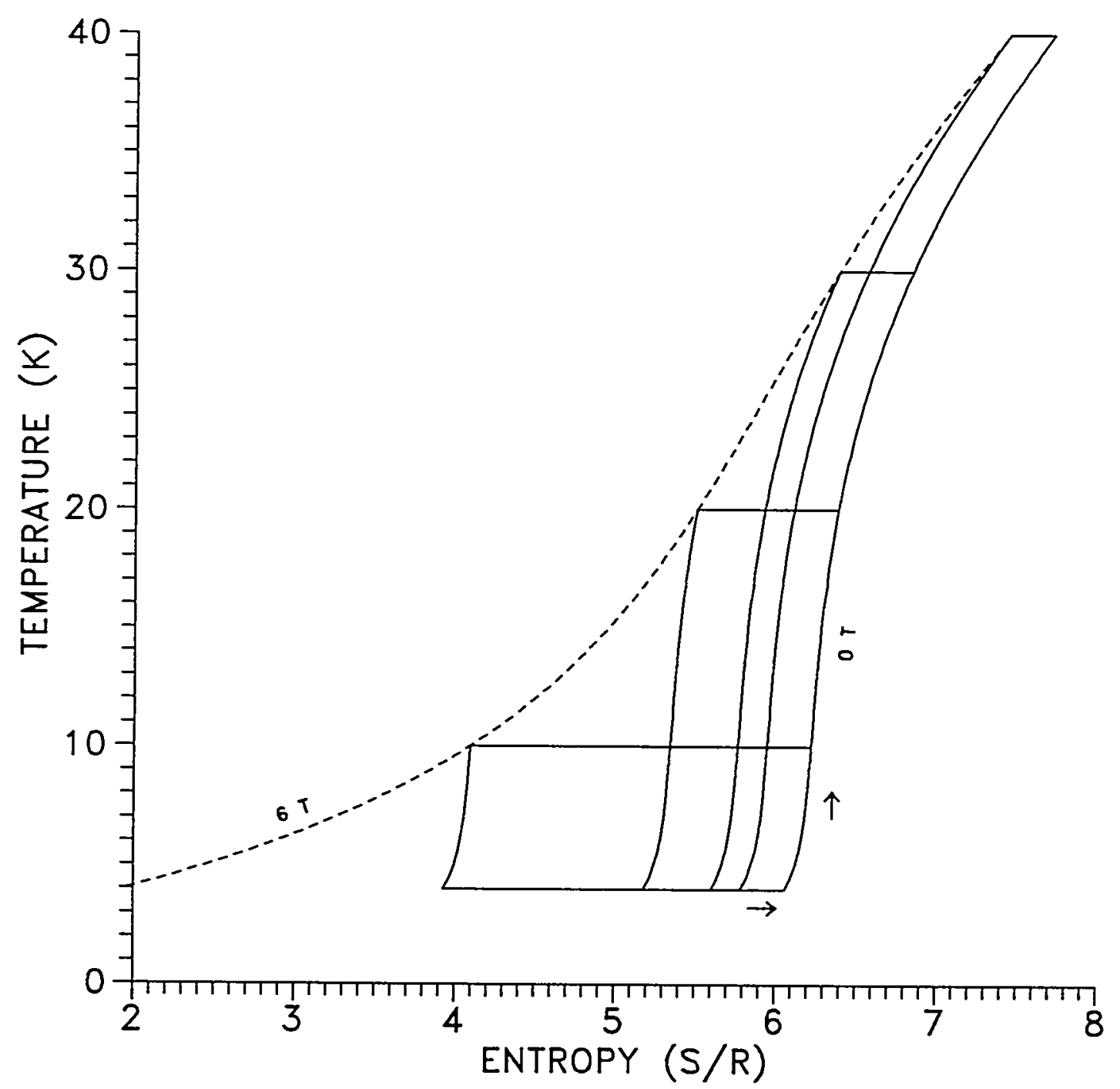

Fig. 10. Sample ideal regenerative cycles. 
regenerative cycle provides cooling capacity that is greater than Carnot at every heat rejection temperature and that, in principle, never vanishes. Because the ideal regenerative cycle also maintains maximum cooling COP, its corresponding heat rejection component (peaking at a heat rejection temperature of $10 \mathrm{~K}$ ) and work input component (peaking at $15 \mathrm{~K}$ ) (Fig. 11) are also larger than those for the Carnot case.

\subsection{PSEUDO-CONSTANT FIELD REGENERATIVE CYCLE}

As pointed out in our earlier studies, if we attempt to execute a cycle comprising two isothermal and two isofield processes, for a material with a property map like that presented here, we find that the amount of heat stored in the regenerator exceeds that removed from it. This result implies that, in the absence of some additional heat sink, such a cycle does not represent steady state system operation. Therefore, to balance the heat stored in and recovered from the regenerator, the high isofield process must be terminated before the cooling temperature is reached, and a segment of adiabatic demagnetization must be added to close the cycle as shown in Fig. 12. Compared with the ideal regenerative cycle described earlier, this cycle shows (1) the same amount of heat rejected at the maximum temperature, (2) the same amount of heat stored in the regenerator, (3) a smaller amount of heat absorbed from the refrigeration load, and (4) a greater amount of work input to the system. Because the last two results imply a reduction in the cooling COP, the net effect of going from the ideal regenerative cycle to the pseudo-constant field regenerative cycle is a decrease in both refrigeration figures of merit: capacity and COP. For the present example, these decreases are attributable solely to the irreversibilities associated with imperfect regeneration.

These trends are illustrated quantitatively in Figs. 13 and 14. As the heat rejection temperature rises above the cooling temperature, the available isothermal entropy change drops less rapidly than for the Carnot case, but more rapidly than for the ideal regenerative case. Thus, the temperature lift range is extended from the Carnot value, but cooling capacity vanishes for a heat rejection temperature between 39 and $40 \mathrm{~K}$ (Fig. 13). For the pseudo-constant field regenerative cycle, the amount of heat rejection is equal to, and therefore the work input (peaking at a heat rejection temperature of $16 \mathrm{~K}$ ) is greater than, the corresponding components for the ideal regenerative cycle. Consequently, the reduction in relative cooling COP is somewhat greater than in relative cooling capacity. In particular, as indicated in Fig. 14 for the conditions of the present example, the cooling COP for the pseudo-constant field cycle drops below $50 \%$ of the COP for the ideal regenerative cycle as the heat rejection temperature approaches $30 \mathrm{~K}$, while the corresponding point for cooling capacity is nearly $31 \mathrm{~K}$ 


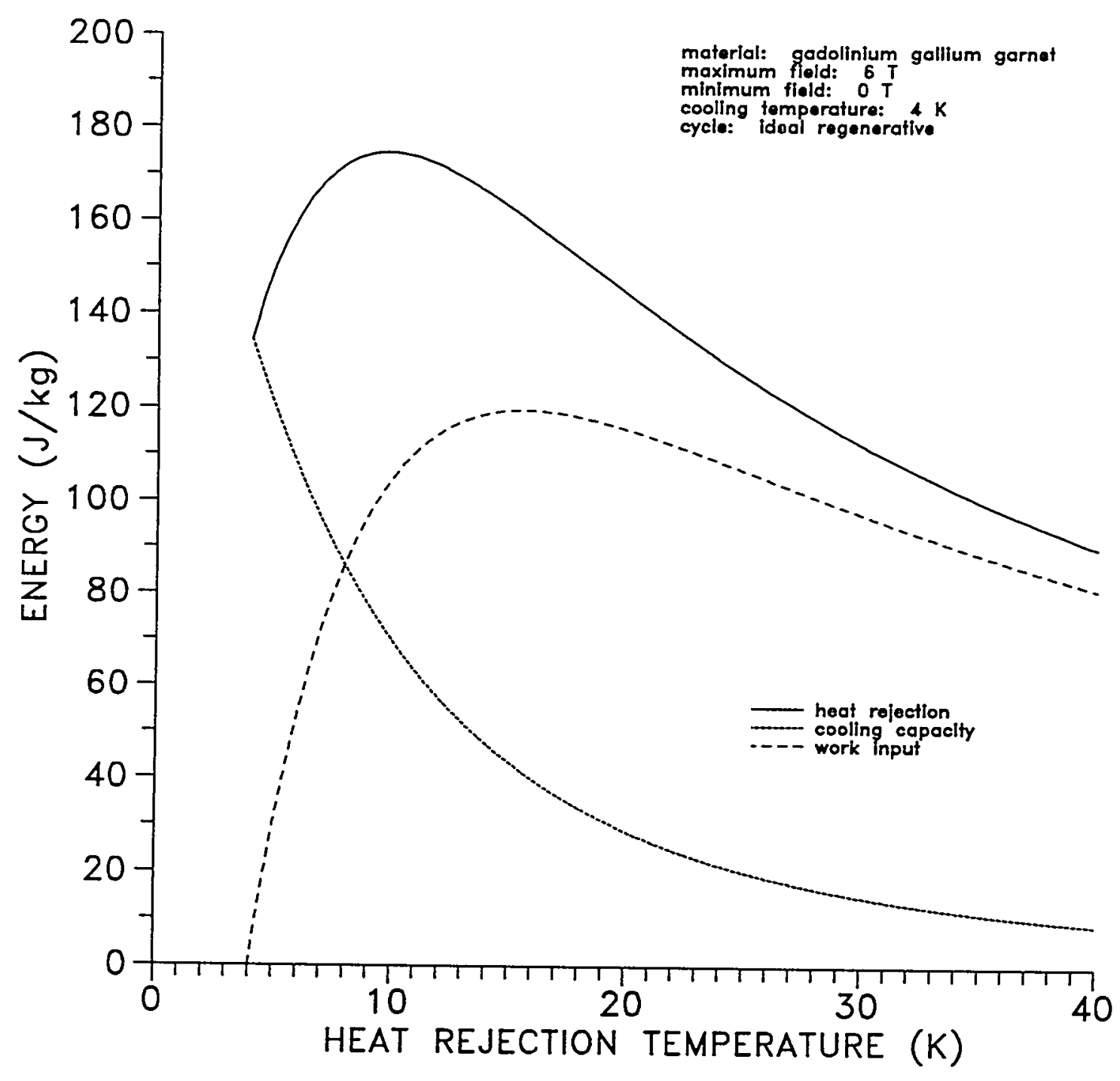

Fig. 11. Energy flows for ideal regenerative cycles. 


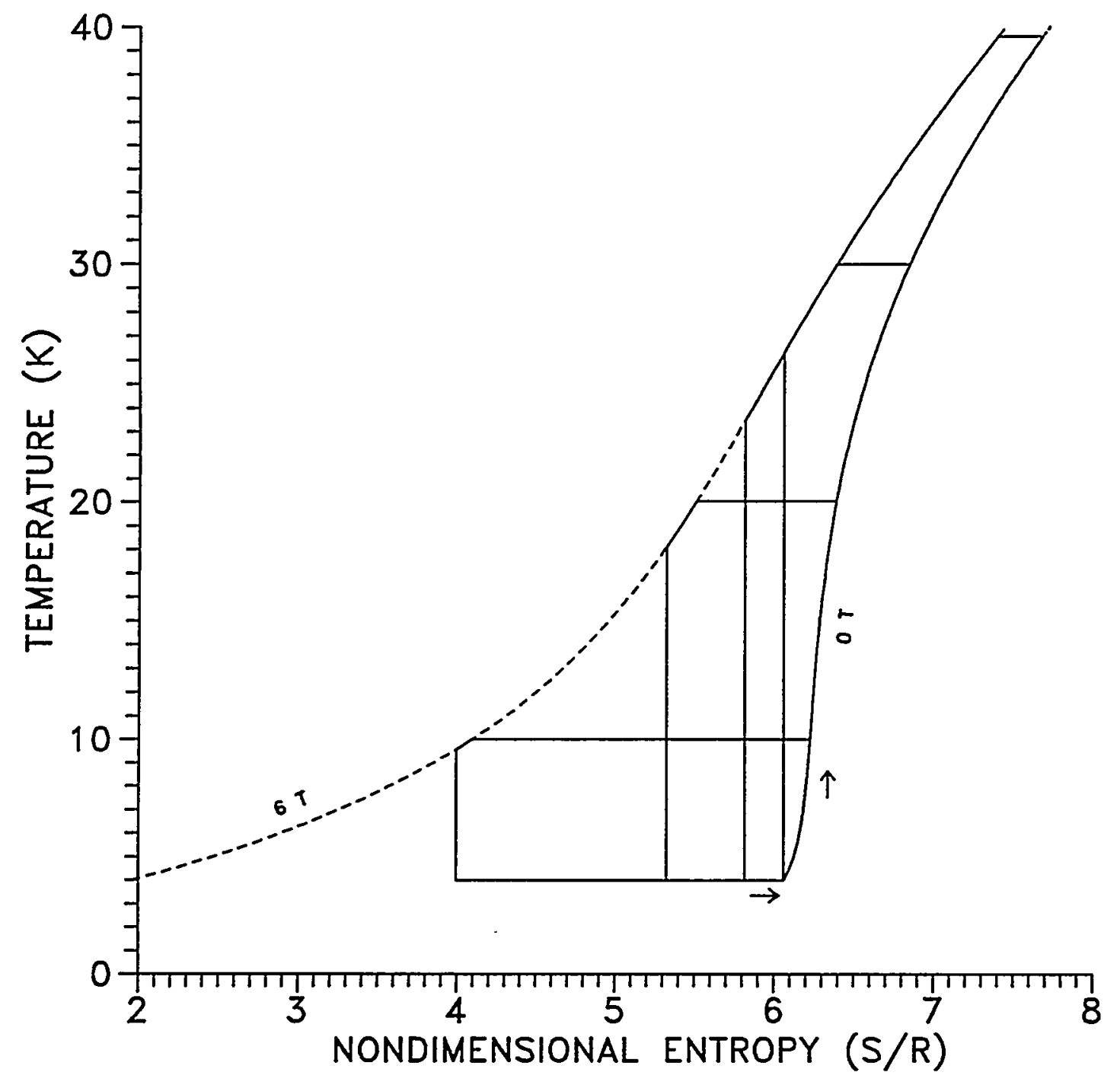

Fig. 12. Sample pseudo-constant field cycles. 


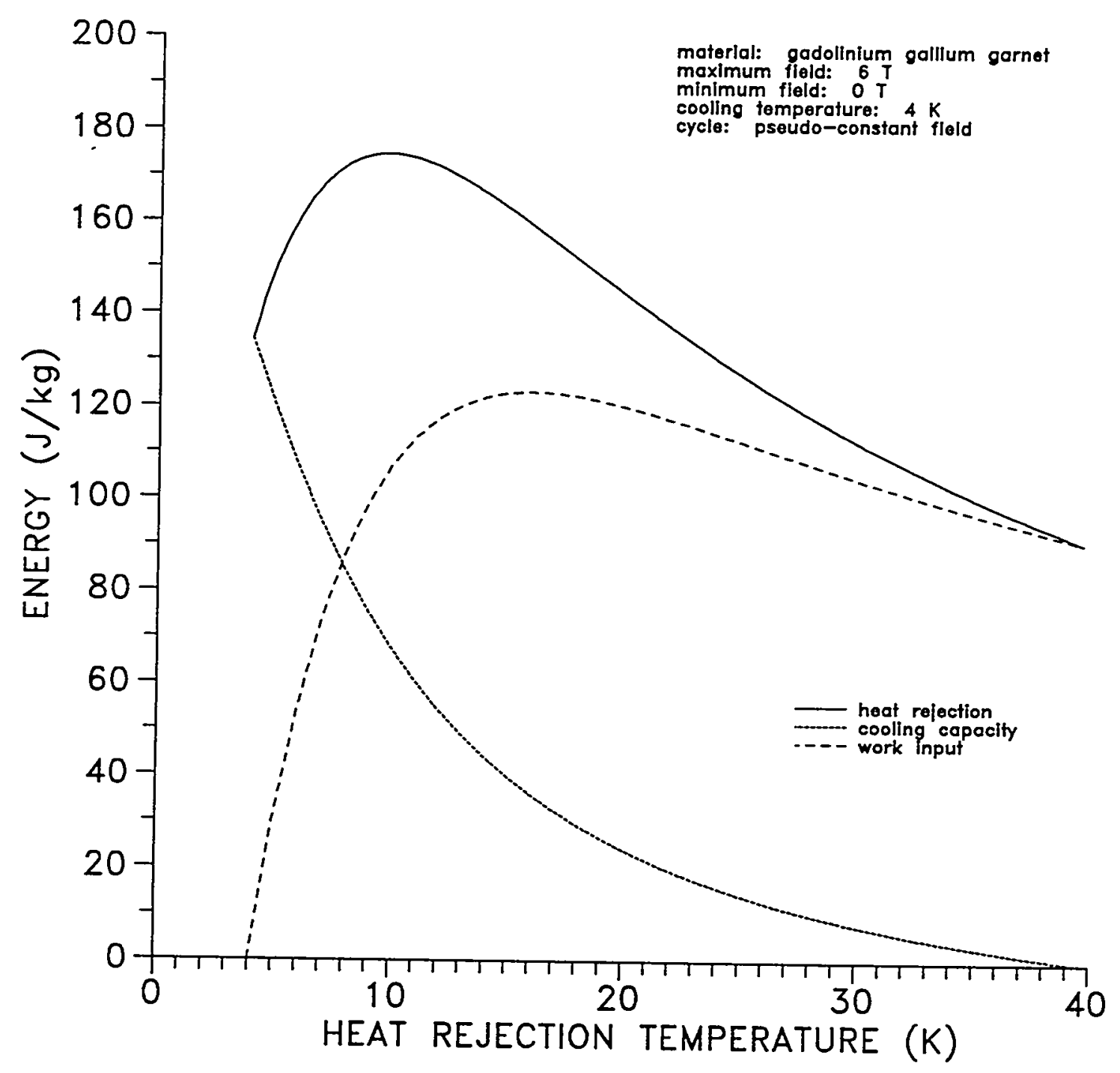

Fig. 13. Energy flows for pseudo-constant field cycles. 


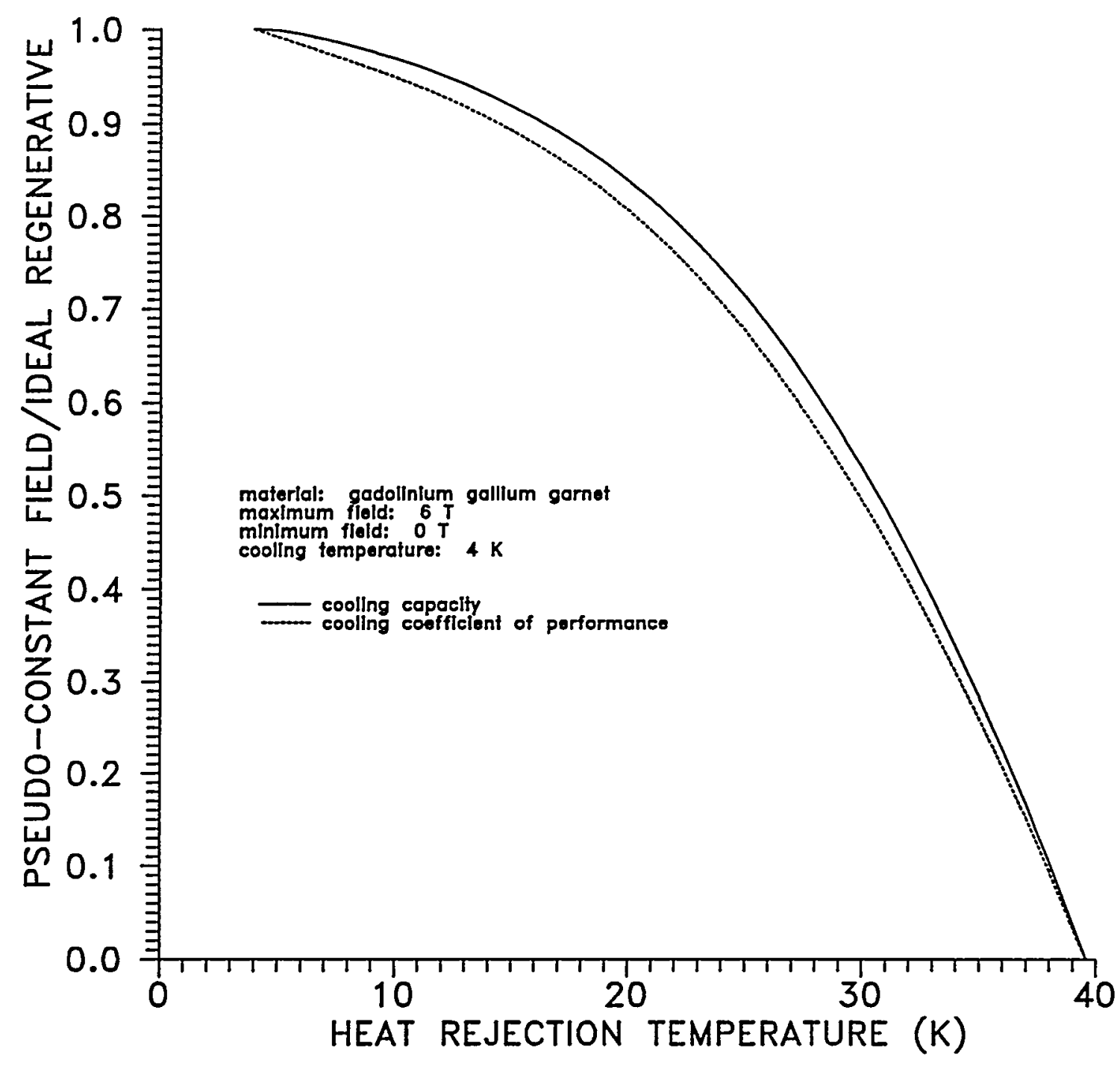

Fig. 14. Relative performance of ideal regenerative and pseudo-constant field cycles. 


\section{CONCLUSIONS}

Based on the evidence presented here, it appears that the formulation of Price and Mastrup ${ }^{11}$ is the most reliable for modeling GGG in the temperature range $4-40 \mathrm{~K}$ and the magnetic field range 0 $0-6 \mathrm{~T}$. When such a model is applied to Carnot cycle analysis with this material, it shows that imposed temperature lift limitations are not as severe as those found for other materials in the higher temperature ranges previously examined. However, the ideal regenerative cycle can, in principle, provide significant benefits in both temperature lift and cooling capacity for larger temperature ranges. The pseudo-constant field cycle offers smaller benefits because of the irreversibilities inherent in its characteristic regenerative processes. 


\section{REFERENCES}

1. J. A. Barclay and W. A. Steyert, "Materials for Magnetic Refrigeration between $2 \mathrm{~K}$ and $20 \mathrm{~K}$," Cryogenics, 22, 73-80, 1982.

2. D. G. Onn, Horst Meyer, and J. P. Remeika, "Calorimetric Study of Several RareEarth Gallium Garnets," Phys. Rev., 156, 663-70, 1967.

3. R. A. Fisher, G. E. Brodale, E. W. Hornung, and W. F. Giauque, "Magnetothermodynamics of Gadolinium Gallium Garnet. I. Heat Capacity, Entropy, Magnetic Moment from 0.5 to $4.2 \mathrm{~K}$, with Fields to $90 \mathrm{kG}$ along the [100] Axis," J. Chem. Phys., 59, 4652-63, 1973.

4. E. W. Hornung, R. A. Fisher, G. E. Brodale, and W.F. Giauque, "Magnetothermodynamics of Gadolinium Gallium Garnet. II. Heat Capacity, Entropy, Magnetic Moment from 0.5 to $4.2 \mathrm{~K}$, with Fields to $90 \mathrm{kG}$ along the [111] Axis," J. Chem. Phys., 61, 282-91, 1974.

5. G. E. Brodale, E. W. Hornung, R. A. Fisher, and W. F. Giauque, "Magnetothermodynamics of Gadolinium Gallium Garnet. III. Heat Capacity, Entropy, Magnetic Moment from 0.5 to $4.2 \mathrm{~K}$, with Fields to $90 \mathrm{kG}$ along the [110] Axis," J. Chem. Phys., 62, 4041-49, 1975.

6. B. Daudin, R. Lagnier, and B. Salce, "Thermodynamic Properties of the Gadolinium Gallium Garnet, $\mathrm{Gd}_{3} \mathrm{Ga}_{5} \mathrm{O}_{12}$, between 0.05 and $25 \mathrm{~K}$," Journal of Magnetism and Magnetic Materials, 27, 315-22, 1982.

7. A. M. Antyukhov, A. V. Antonov, I. A. Ivanov, and M. I. Volchenkova, "Effect of Dislocations on the Heat Capacity of Gadolinium Gallium Garnets," Sov. Phys. Solid State, 26, 325-26, 1984.

8. T. Hashimoto, T. Numazawa, Y. Watanabe, A. Sato, H. Nakagome, O. Horigami, S. Takayama, and M. Watanabe, "The Magnetic Refrigeration Characteristics of Several Magnetic Refrigerants below $20 \mathrm{~K}$ : I. Magnetocaloric Effects," pp. 26-29 in Proceedings of the 9th Intl. Cryogenic Engineering Conference, 1982.

9. Wen Dai, E. Gmelin, and R. Kremer, "Magnetothermal Properties of Sintered $\mathrm{Gd}_{3} \mathrm{Ga}_{5} \mathrm{O}_{12}$ "J. Phys. D: Appl Phys., 21, 628-35, 1988.

10. G. R. Gallagher, "Analysis of a Magnetically Active Regenerator," M.S. thesis, Massachusetts Institute of Technology, 1986.

11. K. D. Price and F. N. Mastrup, "Magnetic Refrigerator Technology," Vol. I, Final Report, WRDC-TR-90-3034, 1990. 
12. F. C. Chen, R. W. Murphy, V. C. Mei, G. L. Chen, J. W. Lue, and M. S. Lubell, "Loss Analysis of the Thermodynamic Cycle of Magnetic Heat Pumps," ORNL/TM-11608, Martin Marietta Energy Systems, Inc., Oak Ridge National Laboratory, February 1991.

13. F. C. Chen, R. W. Murphy, V. C. Mei, and G. L. Chen, "Performance of Four Magnetic Heat Pump Cycles," pp. 103-115 in Thermo-Physical Aspects of Energy Conversion, AES-Vol. 16, ASME, 1990.

14. R. W. Murphy, V. C. Mei, F. C. Chen, and G. L. Chen, "Analysis of Magnetic Refrigeration Cycles," in Proceedings of the 26th Intersociety Energy Conversion Engineering Conference, Vol. 2, ANS, 1991.

15. W. P. Pratt, Jr., S. S. Rosenblum, W. A. Steyert, and J. A. Barclay, "A Continuous Demagnetization Refrigerator Operating near $2 \mathrm{~K}$ and a Study of Magnetic Refrigerants," Cryogenics, 17, 689-93, 1977. 
Appendix

FORTRAN COMPUTER CODE FOR MODELING MAGNETOTHERMODYNAMIC PROPERTIES OF GADOLINIUM GAIIIUM GARNET 



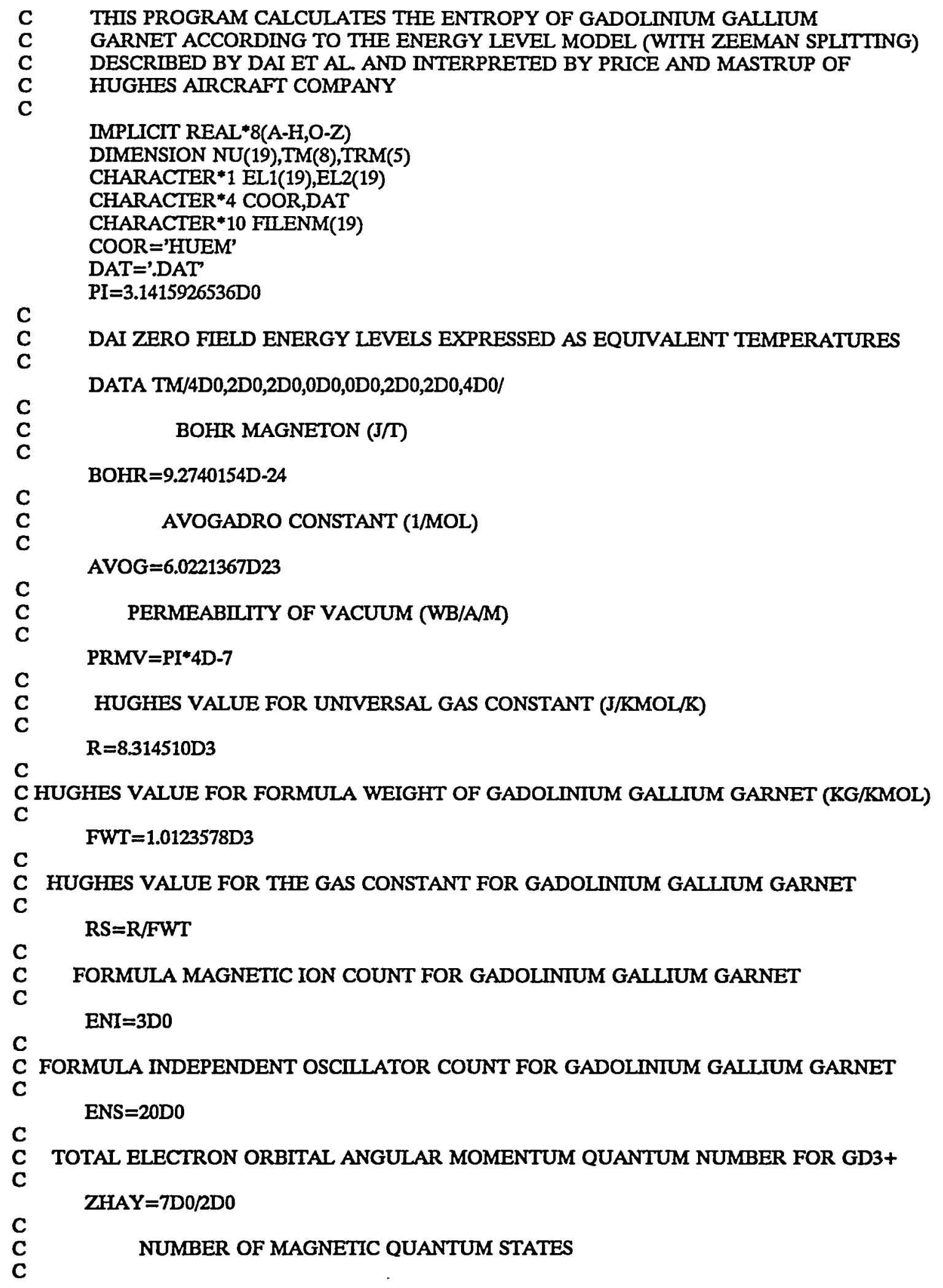




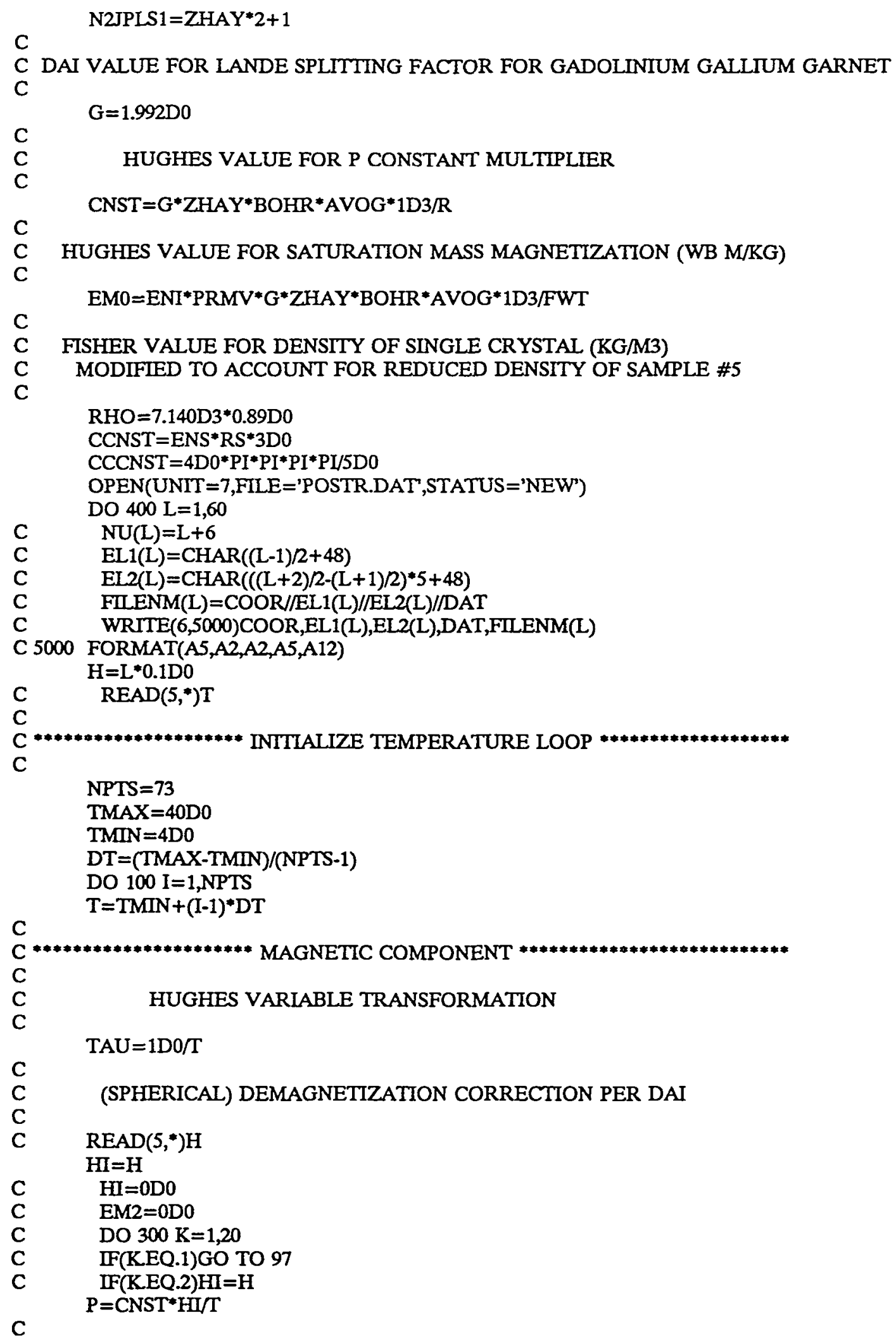




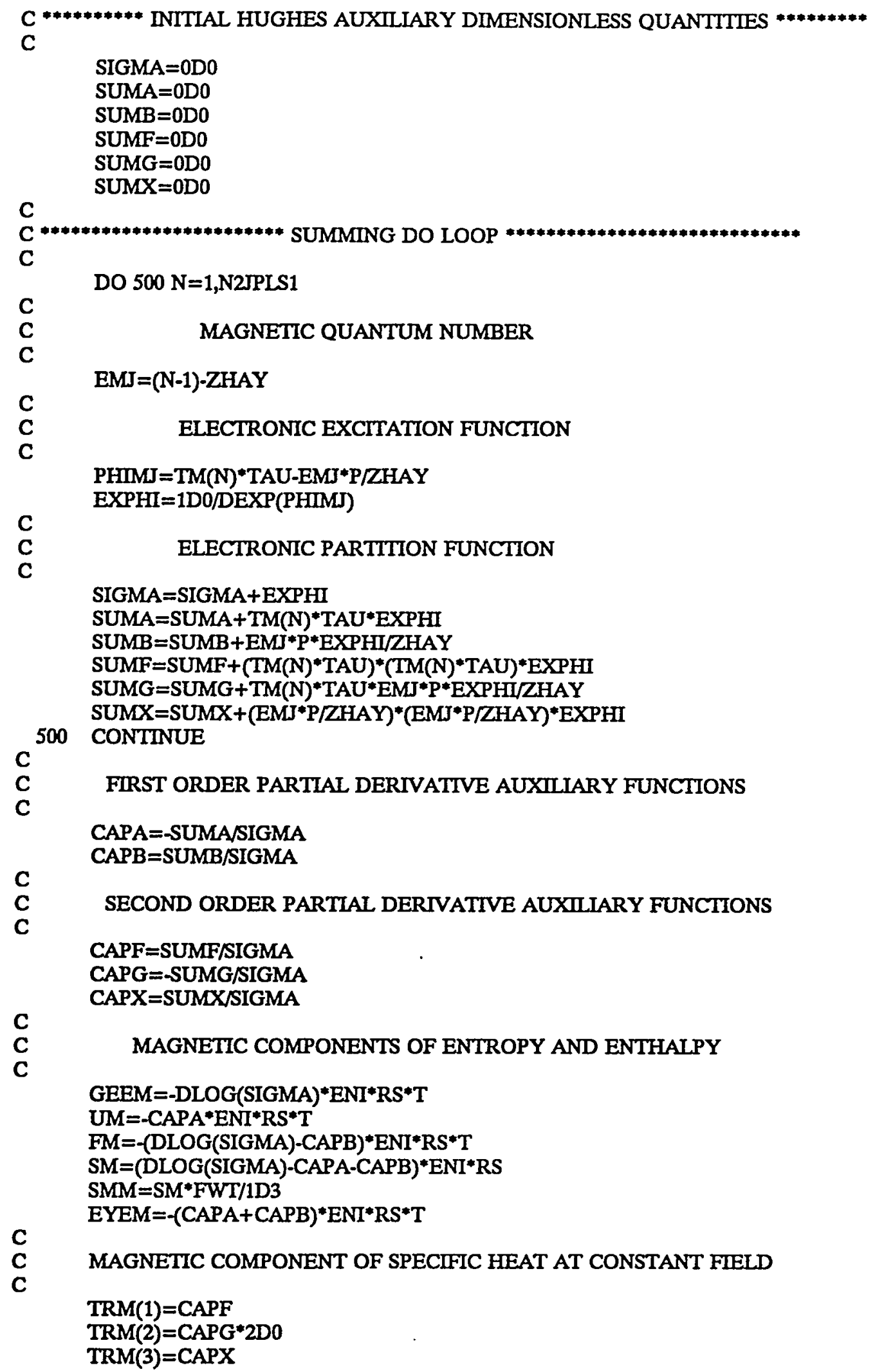

C

C MAGNETIC COMPONENTS OF ENTROPY AND ENTHALPY

C EYEM $=-($ CAPA + CAPB $) * E N I^{*} S^{*} T$

C MAGNETIC COMPONENT OF SPECIFIC HEAT AT CONSTANT FIELD

C

$\operatorname{TRM}(1)=\mathrm{CAPF}$

$\operatorname{TRM}(2)=\mathrm{CAPG}^{*} 2 \mathrm{DO}$

$\operatorname{TRM}(3)=$ CAPX 


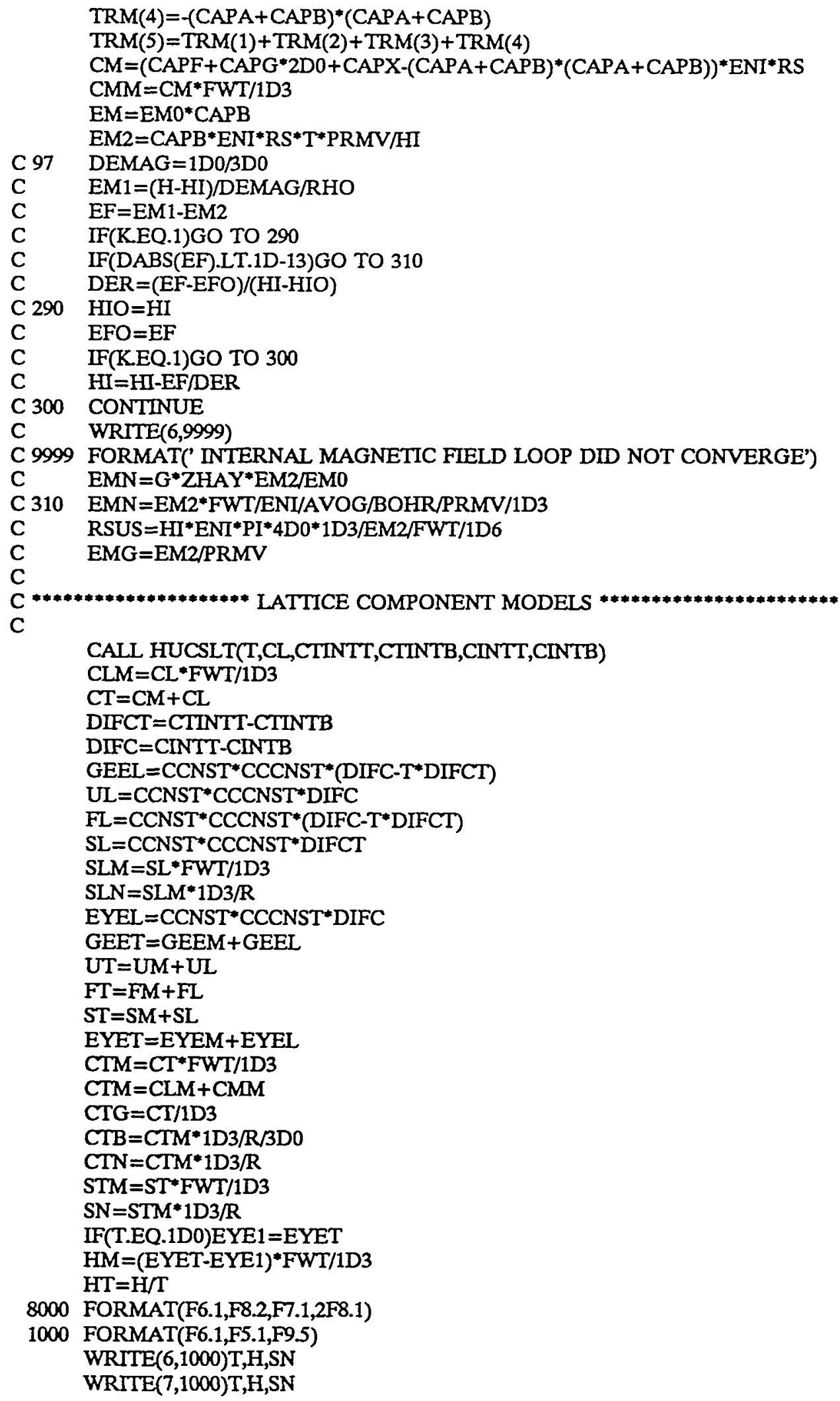




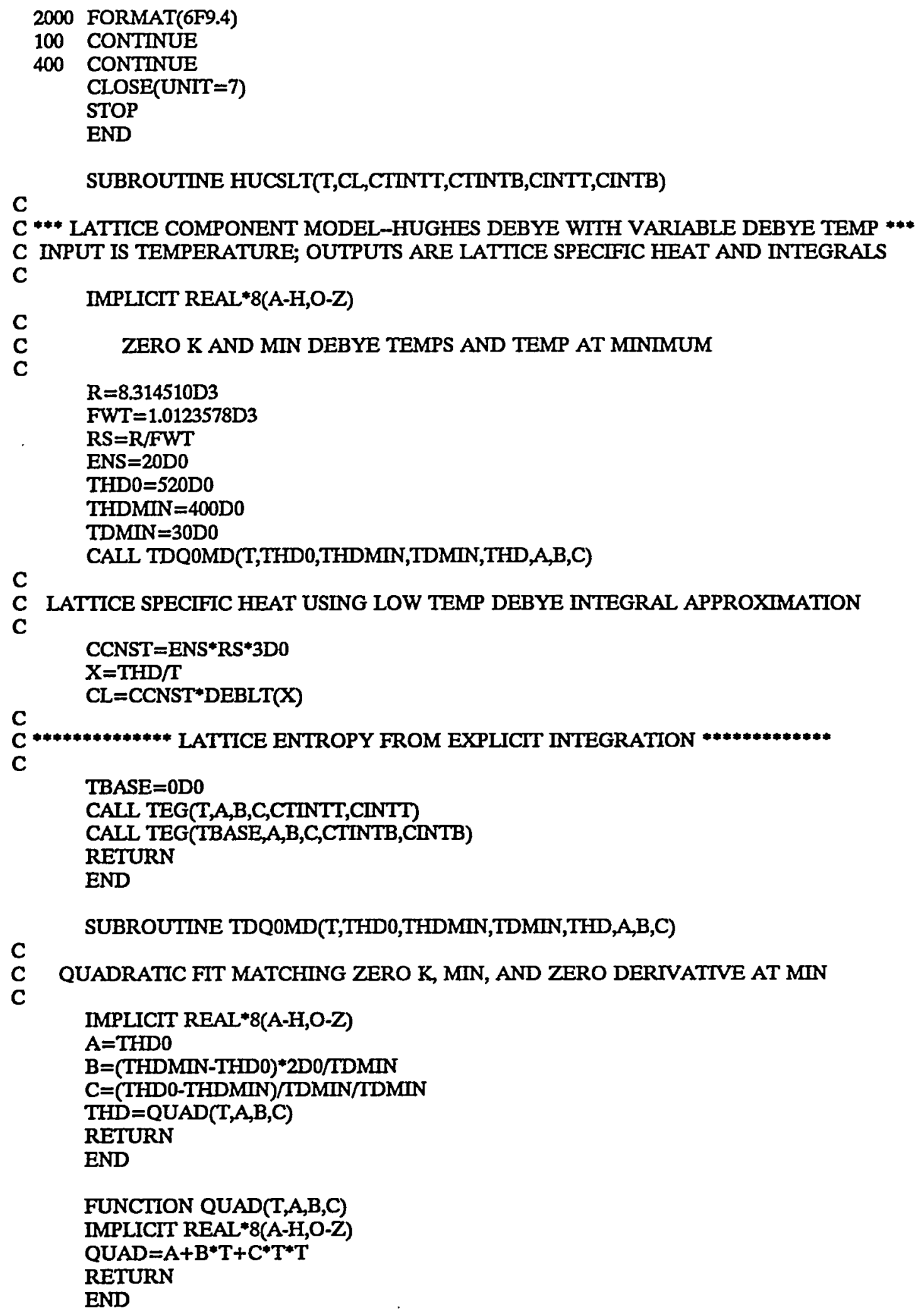


FUNCTION DEBLT(X)

C

C *********** LOW TEMPERATURE DEBYE FUNCTION APPROXIMATION ************

C

IMPLICIT REAL *8(A-H,O-Z)

$\mathrm{PI}=3.1415926536 \mathrm{D} 0$

CCCNST $=4 \mathrm{DO} 0^{*} \mathrm{PI} * \mathrm{PI} * \mathrm{PI}{ }^{*} \mathrm{PI} / 5 \mathrm{D} 0$

DEBLT $=$ CCCNST $/ \mathrm{X} / \mathrm{X} / \mathrm{X}$

RETURN

END

SUBROUTINE TEG(T,A,B,C,CVOVRT,CV)

IMPLICIT REAL $* 8(\mathrm{~A}-\mathrm{H}, \mathrm{O}-\mathrm{Z})$

C

C *** INVERSE QUADRATIC INTEGRATOR BASED ON CRC \#98,\#87,\#90, **********

C

$X=A+B * T+C * T * T$

$Q=4^{*} A^{*} C-B^{*} B$

C

C

C

$$
\mathrm{TM} 1=-\mathrm{T} / \mathrm{C} / \mathrm{X} / \mathrm{X} / \mathrm{BD} 0
$$

$T M 4=-T^{*} T / C / X / X / 2 D 0$

c

C FIRST TERM OF FIRST SUBINTEGRAI BASED ON CRC \#87

C

C

$\mathrm{TM} 21=-\left(\mathrm{A} * 2 \mathrm{D} 0+\mathrm{B}^{*} \mathrm{~T}\right) / \mathrm{Q} / \mathrm{X} / \mathrm{X} / 2 \mathrm{D} 0$

C FIRST SUB-SUB-SUBINTEGRAL BASED ON CRC \#87

C

TEG211 $=2 \mathrm{D} 0 / \mathrm{Q} * * 0.5 \mathrm{D} 0 * \mathrm{DATAN}((\mathrm{C} * \mathrm{~T} * 2 \mathrm{D} 0+\mathrm{B}) / \mathrm{Q} * * 0.5 \mathrm{D} 0)$

C

C

C

C

C

C

TEG2 $=$ TM21-B $* 3 \mathrm{D} 0 / 2 \mathrm{D} 0 / \mathrm{Q} * \mathrm{TEG} 21$

C

C

C

$\mathrm{TM} 2=-\mathrm{B} / \mathrm{C} / 3 \mathrm{D} 0 * \mathrm{TEG} 2$

TM5 $=$ A/C* TEG2

$\mathrm{C}$

C FIRST FACTOR OF FIRST TERM OF SECOND SUBINTEGRAL BASED ON CRC \#91

C

$$
T M 311=(C * T * 2 D 0+B) / Q
$$

C

C

C

C FIRST TERM OF SECOND SUBINTEGRAL BASED ON CRC \#91

C

C

$\mathrm{TM} 31=\mathrm{TM} 311 * \mathrm{TM} 312$ 


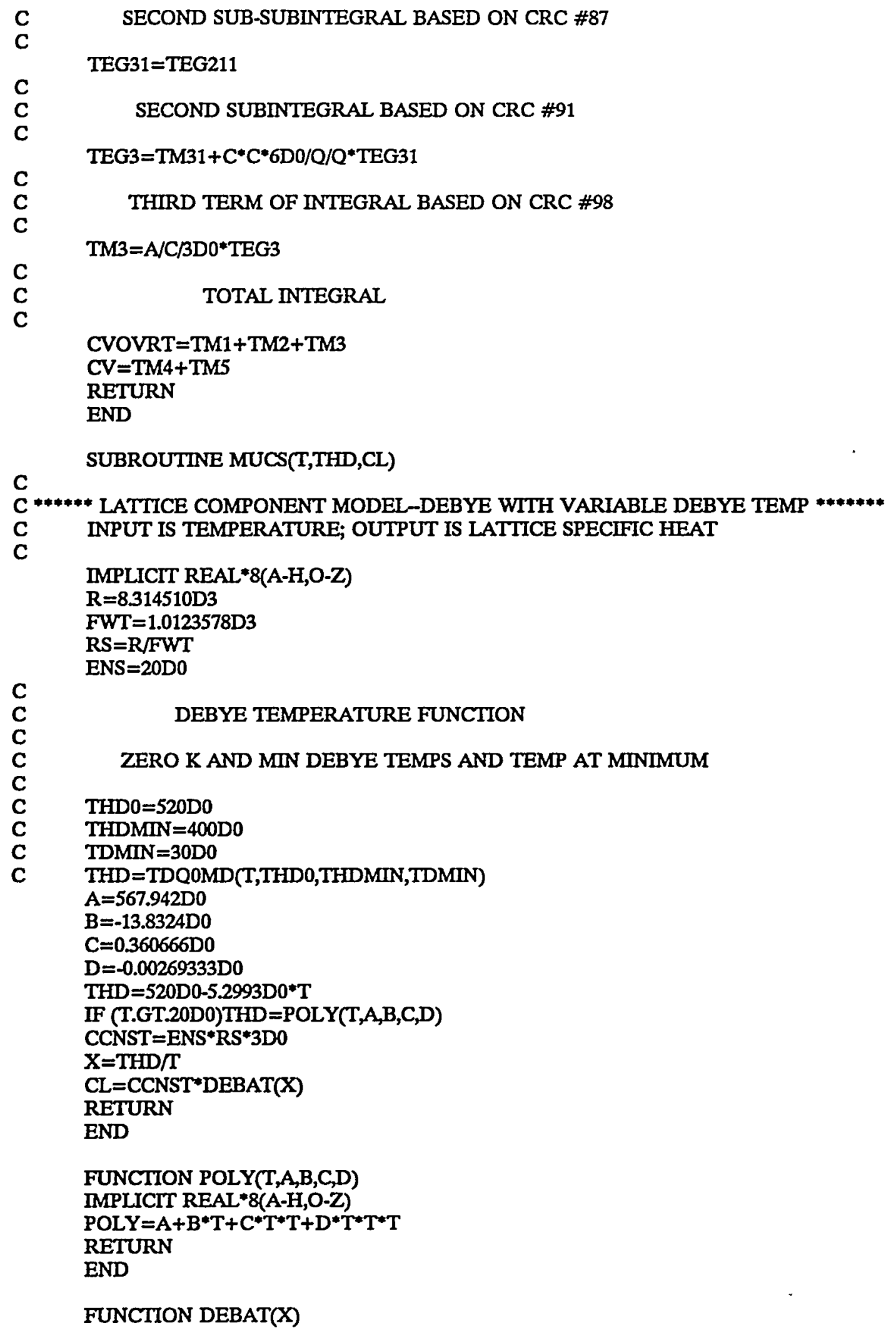

FUNCTION DEBAT(X) 


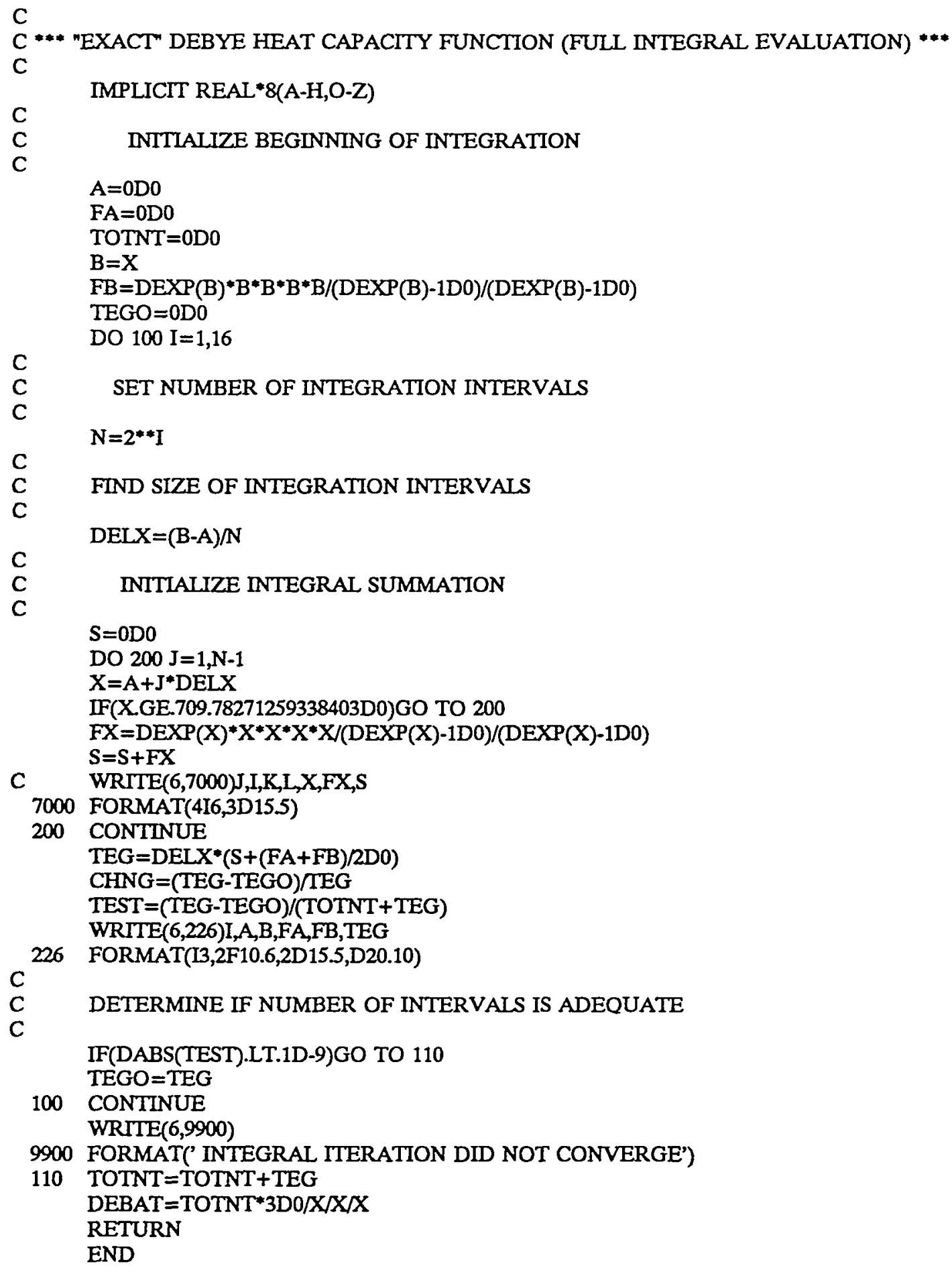




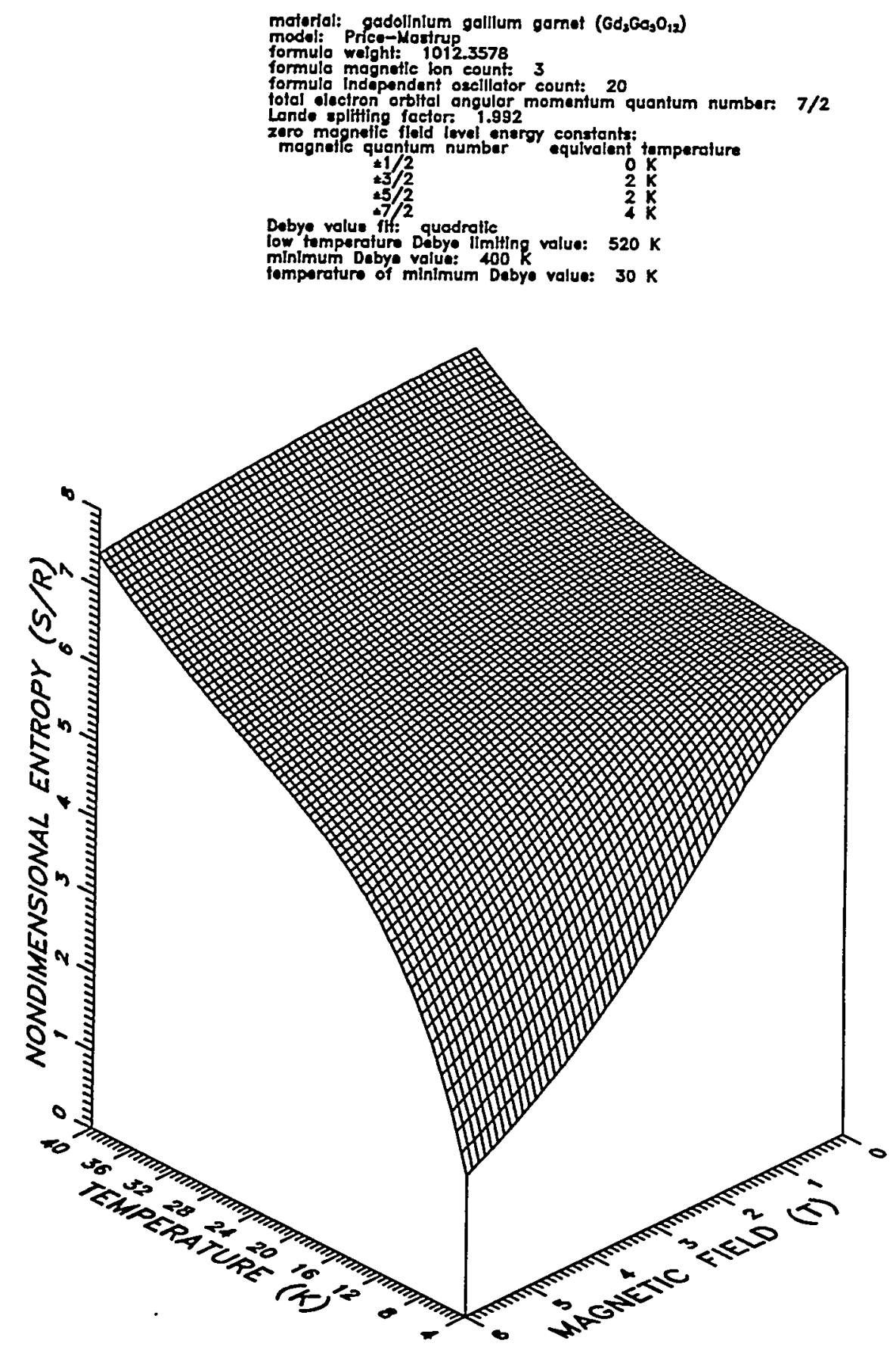

Fig. 15. Entropy/temperature/magnetic field surface. 
ORNL/TM-12664

\section{INTERNAL DISTRIBUTION}

1. M. D. Bunner

2. F. C. Chen

3. D. M. Counce

4. G. E. Courville

5. R. A. Hawsey

6. M. S. Lubell

7. V. C. Mei

8-27. R. W. Murphy
28. A. C. Schaffhauser

29. R. B. Shelton

30. P. P. Wolff

31. ORNL Patent Office

32. Central Research Library

33. Document Reference Section

34-35. Laboratory Records

36. Laboratory Records - RC

\section{EXTERNAL DISTRIBUTION}

37. J. A. Barclay, Department of Mechanical Engineering, University of Victoria, P.O. Box 3055, Victoria, British Columbia V8W3P6, Canada

38. D. R. Bohi, Director, Energy and Natural Resources Division, Resources for the Future, 1616 P Street, NW, Washington, DC 20036

39. H. G. Campbell, Marketing \& Business Development, Babcock \& Wilcox, Naval Nuclear Fuel Division, P.O. Box 785, Lynchburg, VA 24505-0785

40. J. N. Chafe, Carderock Division, Naval Surface Warfare Center, Annapolis Detachment, Code 812, Annapolis, MD 21402-5067

41. J. G. Daley, Program Manager, Superconductivity Systems, Office of Energy Management, Department of Energy, EE-142, 6H-034/FORRESTAL, 1000 Independence Avenue, SW, Washington, DC 20585

42. A. J. DeGregoria, 2 Chippewa Court, Madison, WI 53711

43. T. E. Drabek, Professor, Department of Sociology, University of Denver, Denver, CO 80208-0209

44. R. W. Foster, Astronautics Corporation of America, Astronautics Technology Center, 5800 Cottage Grove Road, Madison, WI 53716

45. G. F. Green, Carderock Division, Naval Surface Warfare Center, Annapolis Detachment, Code 812, Annapolis, MD 21402-5067

46. K. A. Gschneidner, Jr., Rare-earth Information Center, Ames Laboratory, Institute of Physical Research and Technology, Iowa State University, Ames, IA 50011-3020

47. M. E. Gunn, Jr., Director, Office of Energy Management, Department of Energy, EE-14, 5F-064/FORRESTAL, 1000 Independence Avenue, SW, Washington, DC 20585

48. E. P. HuangFu, Program Manager, Advanced Industrial Concepts Division, Department of Energy, EE-232, 5F-059/FORRESTAL, 1000 Independence Avenue, SW, Washington, DC 20585

49. R. O. Hultgren, Deputy Assistant Manager, Energy Research and Development, Department of Energy, Oak Ridge National Laboratory, P.O. Box 2008, Oak Ridge, TN 37831-6269

50. S. F. Kral, Project Manager-SMES, Accelerator \& Magnet Systems, Babcock \& Wilcox, Naval Nuclear Fuel Division, P.O. Box 785, Lynchburg, VA 24505-0785

51. C. D. MacCracken, President, Calmac Manufacturing Corporation, 101 West Sheffield Avenue, P.O. Box 710, Englewood, NJ 07631 
52. M. J. Nilles, Senior Principal Engineer, Accelerator \& Magnet Systems, Babcock \& Wilcox, Naval Nuclear Fuel Division, P.O. Box 785, Lynchburg, VA 24505-0785

53-54. Office of Scientific and Technical Information, P.O. Box 62, Oak Ridge, TN 37831

55. D. T. Shaw, Director, New York State Institute on Superconductivity, 330 Bonner Hall, State University of New York at Buffalo, Amherst, NY 14260

56. J. B. Shrago, Director, Office of Technology Transfer, 405 Kirkland Hall, Vanderbilt University, Nashville, TN 37240

57. R. D. Shull, Magnetic Materials Group, National Institute of Standards and Technology, Gaithersburg, MD 20899

58. J. L. Smith, Jr., Ford Professor of Engineering, Department of Mechanical Engineering, Cryogenic Engineering Laboratory, Room 41-204, Massachusetts Institute of Technology, Cambridge, MA 02139-4307

59. G. F. Sowers, Senior Vice President, Law Companies Group, Inc., 114 Townpark Drive, Suite 250, Kennesaw, GA 30144-5599

60. C. M. Walton, Ernest H. Cockrell Centennial Chair in Engineering and Chairman, Department of Civil Engineering, University of Texas at Austin, Austin, TX 78712-1076

61. C. B. Zimm, Astronautics Corporation of America, Astronautics Technology Center, 5800 Cottage Grove Road, Madison, WI 53716 